\title{
Nonsense-mediated RNA decay and its bipolar function in cancer
}

\author{
Gonçalo Nogueira ${ }^{1,2}$, Rafael Fernandes ${ }^{1,2}$, Juan F. García-Moreno ${ }^{1,2}$ and Luísa Romão ${ }^{1,2^{*}}$ (D)
}

\begin{abstract}
Nonsense-mediated decay (NMD) was first described as a quality-control mechanism that targets and rapidly degrades aberrant mRNAs carrying premature termination codons (PTCs). However, it was found that NMD also degrades a significant number of normal transcripts, thus arising as a mechanism of gene expression regulation. Based on these important functions, NMD regulates several biological processes and is involved in the pathophysiology of a plethora of human genetic diseases, including cancer. The present review aims to discuss the paradoxical, pro- and anti-tumorigenic roles of NMD, and how cancer cells have exploited both functions to potentiate the disease. Considering recent genetic and bioinformatic studies, we also provide a comprehensive overview of the present knowledge of the advantages and disadvantages of different NMD modulation-based approaches in cancer therapy, reflecting on the challenges imposed by the complexity of this disease. Furthermore, we discuss significant advances in the recent years providing new perspectives on the implications of aberrant NMD-escaping frameshifted transcripts in personalized immunotherapy design and predictive biomarker optimization. A better understanding of how NMD differentially impacts tumor cells according to their own genetic identity will certainly allow for the application of novel and more effective personalized treatments in the near future.

Keywords: Nonsense-mediated RNA decay (NMD), Cancer therapy, Immunotherapy, Neoantigen, Biomarker, Tumor suppressor gene, Oncogene, Environmental stress, Tumor microenvironment
\end{abstract}

\section{Background}

Eukaryotic gene expression comprises a series of interconnected steps in which messenger RNAs (mRNAs) play a crucial intermediate role. To ensure that the genetic information is correctly transcribed from DNA to RNA, and then translated into a functional protein, eukaryotic cells have developed several elaborate quality control mechanisms, many of them acting precisely at the mRNA level $[1,2]$. The nonsense-mediated RNA decay (NMD) is one of those mechanisms. NMD recognizes and degrades transcripts harboring a premature translation-termination codon (PTC), preventing the

\footnotetext{
* Correspondence: luisa.romao@insa.min-saude.pt

1 Departamento de Genética Humana, Instituto Nacional de Saúde Doutor Ricardo Jorge, 1649-016 Lisbon, Portugal

${ }^{2}$ BiolSI - Instituto de Biossistemas e Ciências Integrativas, Faculdade de Ciências, Universidade de Lisboa, 1749-016 Lisbon, Portugal
}

production of $\mathrm{C}$-terminally truncated proteins that can have a deleterious effect in the cell $[3,4]$. PTCs can be introduced by mutations in the DNA, such as nonsense or frameshift mutations, or by errors in the mRNA processing $[5,6]$, and are associated with several diseases, such as $\beta$-thalassemia, cystic fibrosis, Duchenne's muscular dystrophy and cancer [6, 7]. Indeed, it is estimated that $30 \%$ of the human genetic diseases are caused by PTC-introducing mutations that, therefore, can be promoted by NMD activity [7]. On other note, transcriptome-wide analyses have revealed that NMD also regulates the abundance of a large number of physiological mRNAs that encode full-length proteins ( $\sim 10 \%$ of human wild-type coding genes), suggesting a significant role in gene expression regulation [8-17]. In this regard, NMD function has been implicated in the

(c) The Author(s). 2021 Open Access This article is licensed under a Creative Commons Attribution 4.0 International License, which permits use, sharing, adaptation, distribution and reproduction in any medium or format, as long as you give appropriate credit to the original author(s) and the source, provide a link to the Creative Commons licence, and indicate if changes were made. The images or other third party material in this article are included in the article's Creative Commons licence, unless indicated otherwise in a credit line to the material. If material is not included in the article's Creative Commons licence and your intended use is not permitted by statutory regulation or exceeds the permitted use, you will need to obtain permission directly from the copyright holder. To view a copy of this licence, visit http://creativecommons.org/licenses/by/4.0/ The Creative Commons Public Domain Dedication waiver (http://creativecommons.org/publicdomain/zero/1.0/) applies to the data made available in this article, unless otherwise stated in a credit line to the data. 
regulation of many essential biological processes related to organism development, cell differentiation, cell stress and immune responses [18]. Disruption of the NMD mechanism can lead to pathologies, including neurological disorders, immune diseases and cancer.

The involvement of NMD in cancer development has been extensively studied during the past few years. It was shown that different cancer contexts can take advantage of both NMD quality-control and regulatory functions to potentiate the development of the disease [2]. For example, tumor-suppressor genes were shown to be prone to exhibit NMD-inducing features [19], providing an opportunity for NMD to control their expression and potentiate cells sensibility to cancer development [20-25]. On the other hand, NMD was shown to downregulate the expression of many important factors that can aid tumorigenesis, including proteins involved in cell growth, cell cycle, apoptosis and cell migration [26]. In line with this, in some tumors, NMD factors contain disabling mutations that lead to the impairment of NMDmediated degradation and its protective role against tumorigenesis [27, 28].

The present review describes NMD as a major surveillance and gene expression regulatory pathway, by briefly exposing the knowledge regarding its players, mechanism of action and biological relevance, focusing specifically on cancer. Then, we discuss in detail how tumor cells have explored both the quality and regulatory NMD functions to leverage tumorigenesis in their own microenvironment. We also present the challenges of using NMD in cancer therapy, addressing situations where inhibition or activation of NMD are favorable according to the genetic context of the cancer. Finally, we discuss how NMD inhibition and/or NMD-escaping can contribute for biomarker optimization and personalized immunotherapy design.

\section{NMD pathway}

The molecular mechanism of NMD has been described by several models that differ in some key aspects, while agreeing that it is fundamentally a translation-dependent process. This dependence has been observed over the years using translation inhibition approaches, either by the presence of translation inhibitors (e.g., cycloheximide and puromycin) or extended stem-loops in the $5^{\prime}$ untranslated region (UTR) [29, 30]. Currently, there are two main models that better describe the NMD mechanism: the exon junction complex (EJC)-dependent and the EJC-independent model (Fig. 1) [31], which differ mostly in the involvement of an EJC, a dynamic multiprotein complex, that includes up-frameshift protein $3 \mathrm{~B}$ (UPF3B), an important NMD-factor [32-35]. The EJC is formed during splicing and deposited 20-24 nucleotides (nts) upstream of exon-exon junctions, remaining associated with the mRNA during its transport to the cytoplasm until its displacement by the translating ribosome during the pioneer round of translation [32-34, $36,37]$. In a situation where an mRNA contains a PTC located more than 50-54 nts upstream of the last exonexon junction, the ribosome is unable to displace the downstream EJCs [38, 39], allowing an interaction between the latter and certain NMD factors, thus triggering NMD [38, 40-42].

NMD begins with the arrival of the translating ribosome to a PTC, at which the translation eukaryotic release factors (eRF) 1 and 3 interact with UPF1 and the serine/threonine protein kinase, SMG1, associated with its regulators, SMG8 and SMG9, to form the "SURF" complex (Fig. 1b) [42-44]. Recent evidence places the ATP-dependent RNA helicase DEAH box polypeptide 34 (DHX34) in this complex, operating as a scaffold protein for UPF1-SMG1 interaction [45, 46]. Meanwhile, UPF3B and UPF2 are recruited to interact with UPF1 $[45,46]$, forming the decay-inducing complex (DECID) (Fig. 1c) [44, 47]. The interaction between UPF1, UPF2 and UPF3B leads to conformational changes in UPF1 structure allowing the subsequent SMG1-mediated UPF1 phosphorylation and the exit of the ribosome, the nascent peptide and the release factors (Fig. 1c) [42, 44, 47-53]. For NMD activation to occur, the EJCindependent model depends on the diffusion of UPF2 and UPF3B in the cytoplasm, while the EJC-dependent model relies on their interaction with the EJC downstream of the PTC (Fig. 1a) [31]. However, not all PTCcontaining transcripts are able to induce NMD. For example, when the cytoplasmic poly(A)-binding protein 1 (PABPC1) bound to the poly(A) tail is near the termination complex at the PTC, it can repress NMD by interacting with eRF3 and preventing the UPF1-eRF3 interaction [54-57]. The PABPC1-eRF3 interaction is thought to be essential for normal termination [42, 58, 59]. This competition appears to be more relevant in the EJC-independent NMD mechanism since it relies on UPF2 and UPF3B diffusion [54-57, 60].

The steps following UPF1 phosphorylation are common to both NMD models. Once phosphorylated, UPF1 triggers mRNA decay. First, by taking advantage of its RNA helicase activity to remove the RNA secondary structures and proteins downstream of PTCs [61]. Second, through the recruitment of SMG6, SMG5-7 heterodimer, or SMG5 and PNRC2 (Proline Rich Nuclear Receptor Coactivator 2) (Fig. 1d) [52, 62], causing the dissociation of SMG1, SMG8 and SMG9. Additionally, the protein phosphatase $2 \mathrm{~A}$ (PP2A) dephosphorylates UPF1. The endonuclease activity of SMG6 induces cleavage in the vicinity of the PTC, generating unprotected mRNA ends that will be prone to degradation [63-67]. When SMG5-SMG7 or SMG5-PNRC2 are 


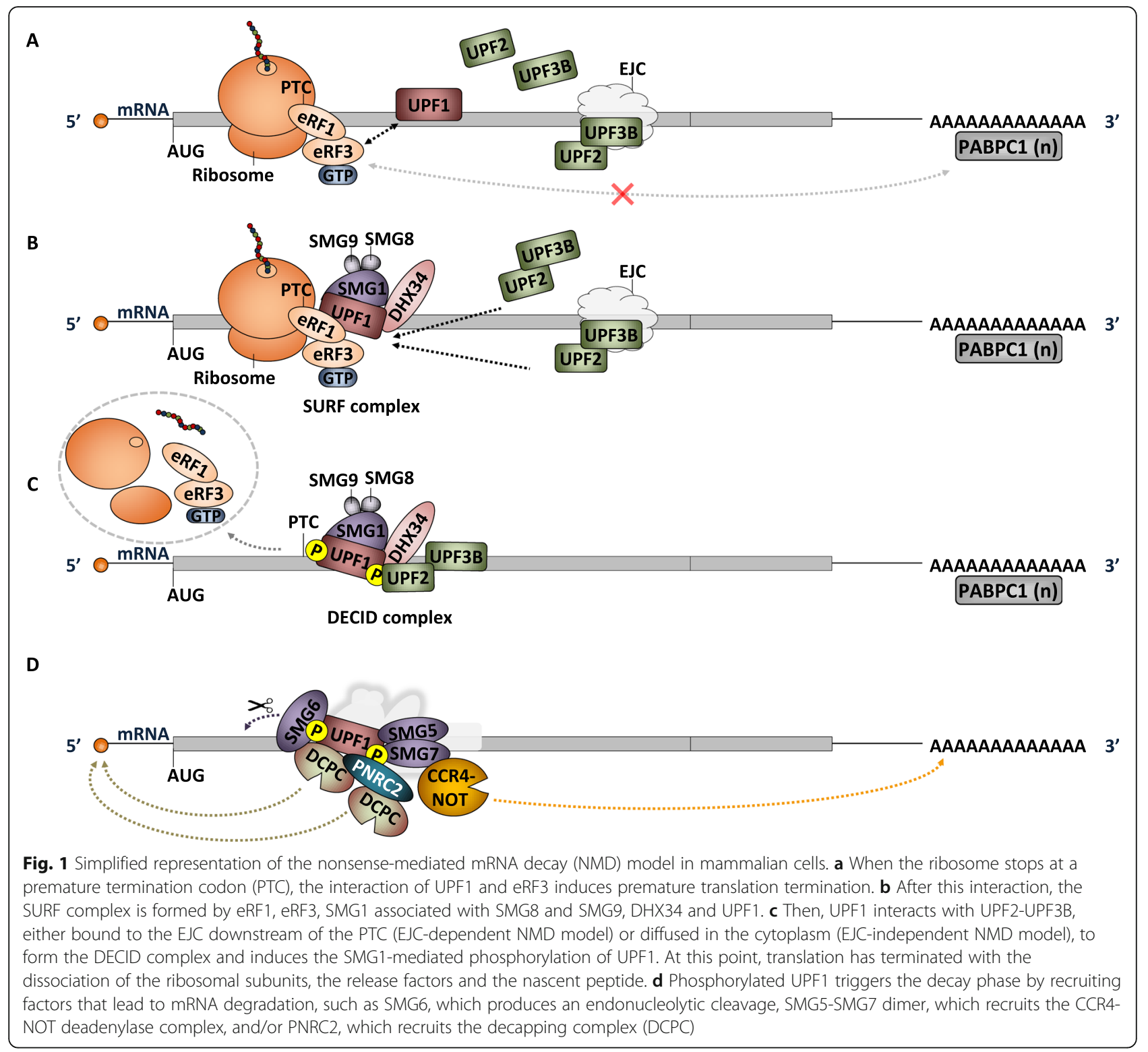

present, these proteins further recruit the decapping complex (DCPC) and the deadenylation complex (CCR4-NOT) to remove the cap-binding complex and the poly(A) tail (Fig. 1d), allowing $5^{\prime}$-to-3' and $3^{\prime}$-to-5' RNA degradation by XRN1 and the RNA exosome, respectively [63, 64, 68-71].

The formation of UPF1-UPF2-UPF3 surveillance complex is believed to activate NMD, however, recent studies by Neu-Yilik et al., presented the possibility that UPF3B, rather than UPF1, interacts with eRF3 to induce peptide release and dissociation of the termination complexes. Moreover, UPF3B was also shown to interact with UPF1, contradicting the need for UPF2 to bring together these two NMD factors [72]. Such findings propose a novel role for UPF3B that requires further testing [73]. In sum, the proper mRNA targeting and decay by the NMD pathway depends on the presence of several proteins in a spatiotemporal manner, as discussed above. Hence, one can expect the existence of less common branches of NMD linked to the regulation of specific targets. In fact, it was shown in higher eukaryotes that, besides de EJC-dependent and independent branches, NMD could also be UPF2-independent and UPF3-independent [34, 74, 75]. In support of this view, Huang et al. found that NMD owns an auto-regulatory feedback loop mechanism that is dependent on the 
different branches of NMD: the UPF3B-dependent branch regulates UPF1 and SMG7 transcripts, the EJCdependent branch regulates UPF1 and SMG5 transcripts, and the UPF2-dependent branch regulates SMG1 mRNA levels [31, 76]. Furthermore, it was found that a splicing factor, SRSF1 (Serine and Arginine Rich Splicing Factor 1), directly interacts with UPF1, enhancing the binding of the latter to the mRNA, thus promoting NMD. Since this event is both UPF3B and UPF2-independent, it might constitute a new NMD branch [77]. In the human organism, it is not known if the efficiency of these NMD branches varies between different tissues.

As mentioned before, the NMD pathway was initially classified as a quality control mechanism responsible for the targeted degradation of aberrant transcripts carrying a PTC. However, during the last decade, several transcriptome-wide studies revealed that NMD also degrades a variety of normal mRNAs that would produce functional proteins. This role classifies NMD as major regulatory mechanism of gene expression, being directly or indirectly responsible for the regulation of $\sim 3-20 \%$ of transcripts in eukaryotes from yeast to mammals [8, $9,11,13-16,34,78,79]$. In an attempt to elucidate why NMD targets these apparently normal transcripts, several studies have reported the existence of NMDinducing features that are responsible for eliciting their decay. For instance, mRNAs with long 3'UTRs have higher probability of eliciting NMD, due to PABPC1 failing to interact with the termination complex [57, 8082]. Another NMD-triggering feature is the presence of at least one exon-exon junction more than 50 nts downstream of the termination codon [83]. An additional feature is the presence of upstream open reading frames (uORFs) in the 5'UTR of the transcripts [84]. In this case, the NMD is triggered by the stop codon of the uORF which is at the $5^{\prime}$-end of the mRNA with downstream EJCs, thus placing it in a premature context [84]. These genomic features are considered the three canonical rules of NMD targeting, yet it is possible for a transcript that carries one or more of these genomic features to evade NMD. The variance in NMD efficiency across thousands of PTCs still requires further elucidation. More recently, based on data from paired cancer exomes and transcriptomes, Lindeboom et al. proposed two additional non-canonical features able to trigger NMD: the long exon rule and the start-proximal rule [21]. In this study, the authors propose that PTCs located in exceptionally long exons ( $>400 \mathrm{nts}$ ) significantly reduce NMD efficiency and that PTCs at $<150$ nts from the start codon in most cases fail to induce NMD, probably due to translation re-initiation at a downstream AUG codon $[21,85]$. In addition, the same authors also observed that PTCs located very far from the normal stop codon induce a low efficient NMD process, which they called "the PTC-to-normal-stop rule" [21, 85]. Furthermore, they found that mRNAs with short half-lives are targets of an inefficient NMD [21, 85]. Still, the same work has shown that the presence of specific cis-acting elements in the mRNA, which can be located either near to the PTC or in the natural UTR of the transcript, can modulate NMD efficiency [21, 85]. These data demonstrate that there are many different genomic features involved in targeting a transcript for NMD. In fact, when certain criteria are met, NMD is able to regulate the levels of a subset of normal transcripts, linking its activity to the regulation of many biological pathways.

\section{NMD biological relevance}

Considering the NMD dual function, one can expect its activity and regulation to be involved in both physiological and pathophysiological mechanisms. In fact, NMD activity has been implicated in several biological processes related to cell differentiation, cell stress and immune responses [18]. Also, NMD presents a special role in modulating human diseases caused by PTCintroducing mutations, as the ones observed in $\beta$ thalassemia, cystic fibrosis, Duchenne's muscular dystrophy and cancer $[6,7]$.

\section{NMD modulates biological processes}

Over the years, a strong correlation between depletion of core NMD factors and embryonic lethality has been established [18, 86-89]. Accordingly, NMD-mediated regulation of two pro-apoptotic factors, GADD45 (Growth Arrest and DNA Damage 45) and GAS5 (Growth Arrest Specific 5), is important to maintain mammalian cell viability and development [90-92]. Moreover, depletion of NMD factors such as UPF2 and UPF3 can, respectively, lead to: defective liver development and regeneration [93], and dysregulation of genes essential for spermatogenesis, causing severe testicular atrophy and male sterility [18, 94-96]. Although NMD seems to play a role in the regulation of these processes, we cannot exclude the possibility that other mechanisms are operating and contributing to the phenotype $[97,98]$. An example occurs in myogenesis, where the competition between NMD and STAU-mediated decay (SMD) for the exclusive interaction with UPF1 was shown to be essential [97, 98]. During differentiation from myoblasts to myotubes NMD activity decreases to upregulate the promyogenic transcription factor, myogenin, while SMD efficiency increases, downregulating the antimyogenic factor PAX3 (Paired Box Gene 3) [97, 98].

NMD has also been implicated in the proliferation/differentiation of cells during brain development [99]. If stimulated, NMD inhibits neural differentiation and 
sustains a proliferative state [99]. Accordingly, it was shown that during neural development, NMD activity is downregulated by microRNAs to allow upregulation of transcripts encoding proteins important for neural differentiation and maturation processes [100]. Mutations in NMD factors can lead to dysregulation of genes related to neural function, implicating NMD in neural pathologies such as X-linked intellectual disability, schizophrenia and autism [10, 101-103].

Several studies have also linked NMD function to different stress conditions, such as amino acid starvation, hypoxia, reactive oxygen species (ROS) and ER stress [14, 26, 104-108]. In response to different stress stimuli, specific kinases are activated to phosphorylate the eukaryotic initiation factor-2 $\alpha$ (eIF2 $\alpha)$ [107]. Phosphorylation of eIF2 $\alpha$ affects its interaction with the GTP-GDP exchange factor eIF2B, resulting in low availability of the eIF2 ternary complex (eIF2-GTP-tRNAi) which causes a general reduction in protein synthesis, and thus, in NMD activity [8, 105, 106, 108-112]. Alternatively, data suggests that eIF $2 \alpha$ phosphorylation also promotes formation of cytoplasmic stress granules and relocalization of NMD components into these granules, resulting in a spatial separation between untranslated mRNAs and the RNA degradation machinery that represses NMD activity $[8,105,106,108-111]$. Accordingly, it was shown that numerous stress-related mRNAs are targeted by NMD under basal conditions, and that during stress, NMD inactivation promotes their upregulation to solve the stress $[8,110-112]$. Among these targets are important factors of the stress-response pathways, the integrated stress response (ISR) and the unfolded protein response (UPR), such as the transcription factors, ATF4 (Activating Transcription Factor 4), ATF3 (Activating Transcription Factor 3) and CHOP (CCAAT-EnhancerBinding Protein Homologous Protein) [105, 106, 109, 113]. Here, we discussed a possible mechanism by which stress responses impact NMD, but it is important to know if other mechanisms are also involved. Furthermore, it could be interesting to explore these mechanisms in order to develop novel therapies for those diseases associated with cellular stress conditions, including cancer.

NMD has also been shown to play a relevant role in viral replication, since the abrogation of this pathway culminates in the upregulation of viral proteins and subsequent higher viral infection, indicating that NMD plays a host protective role in blocking virus replication, such as the Semliki Forest virus (SFV) and Sindbis virus (SINV) [114]. In response, some viruses have evolved mechanisms to evade or inhibit NMD: the Rous sarcoma virus has a stability element (RSE) in its 3'UTR that protects the viral RNA, and the HTLV-1 virus expresses two proteins, Tax and Rex, that inhibit NMD $[115,116]$.
The physiological relevance of NMD is further expanded by its connection with alternative splicing (AS) $[117,118] . \mathrm{AS}$ is the greatest contributor to proteome diversity in the cell by generating distinct mRNA isoforms from a single pre-mRNA [119-121]. AS is also the molecular mechanism that generates most of the natural NMD-targets, being estimated that around one third of all AS events results in PTC-containing transcripts [122, 123]. The coupling of AS to NMD (AS-NMD) constitutes a conserved post-transcriptional mechanism of gene expression regulation, that balances the ratio of productive and unproductive mRNA isoforms [117]. Ultimately, this coordinated process leads to regulated protein synthesis, by sorting which of the already transcribed premRNAs will end in a mature mRNA proper for translation. Several AS patterns render NMD-sensitive mRNA isoforms, like exon inclusion and skipping, intron retention in the 3'UTR, or alternative usage of $5^{\prime}$ or 3' splice sites (Fig. 2) [124, 125].

Splicing factors are key mediators of AS-NMD by shifting the balance of which splice sites are recognized, in order to promote transcripts bearing inframe nonsense codons, or PTC-free isoforms [117]. Interestingly, several splicing factors use AS-NMD to regulate their own expression through autoregulatory negative feedback loops by binding to their own transcripts and promoting the production of NMDsensitive isoforms [126-134]. This phenomenon has been described for numerous members of the serine arginine-rich (SR) proteins and heterogeneous nuclear ribonucleoproteins (hnRNPs) [126-130]. Frequently, serine and arginine-rich (SR) proteins act as splicing activators [131, 132], as observed for SRSF2 which targets its own transcript to favor the inclusion of an exon bearing a PTC, hence yielding an NMDsensitive isoform [126]. In contrast, most hnRNPs function as splicing repressors, promoting exon skipping, as reported for the polypyrimidine tract-binding protein 1 (PTBP1) [129, 135]. Besides these splicing factor families, autoregulation by AS-NMD has been also observed in other RBPs, like core spliceosomal components and ribosomal proteins [133-135]. Altogether, these data constitute strong evidence that AS-NMD is a determinant post-transcriptional mechanism that is essential to control gene expression and strongly impacting the transcriptome.

\section{NMD modulates disease phenotype}

As NMD has a key role in mRNA surveillance, it is not surprising that its activity has been implicated in the phenotype modulation of several human genetic diseases $[6,7]$. For instance, the $\beta$-thalassemia, a well-known inherited severe anemia caused by low levels of normally 


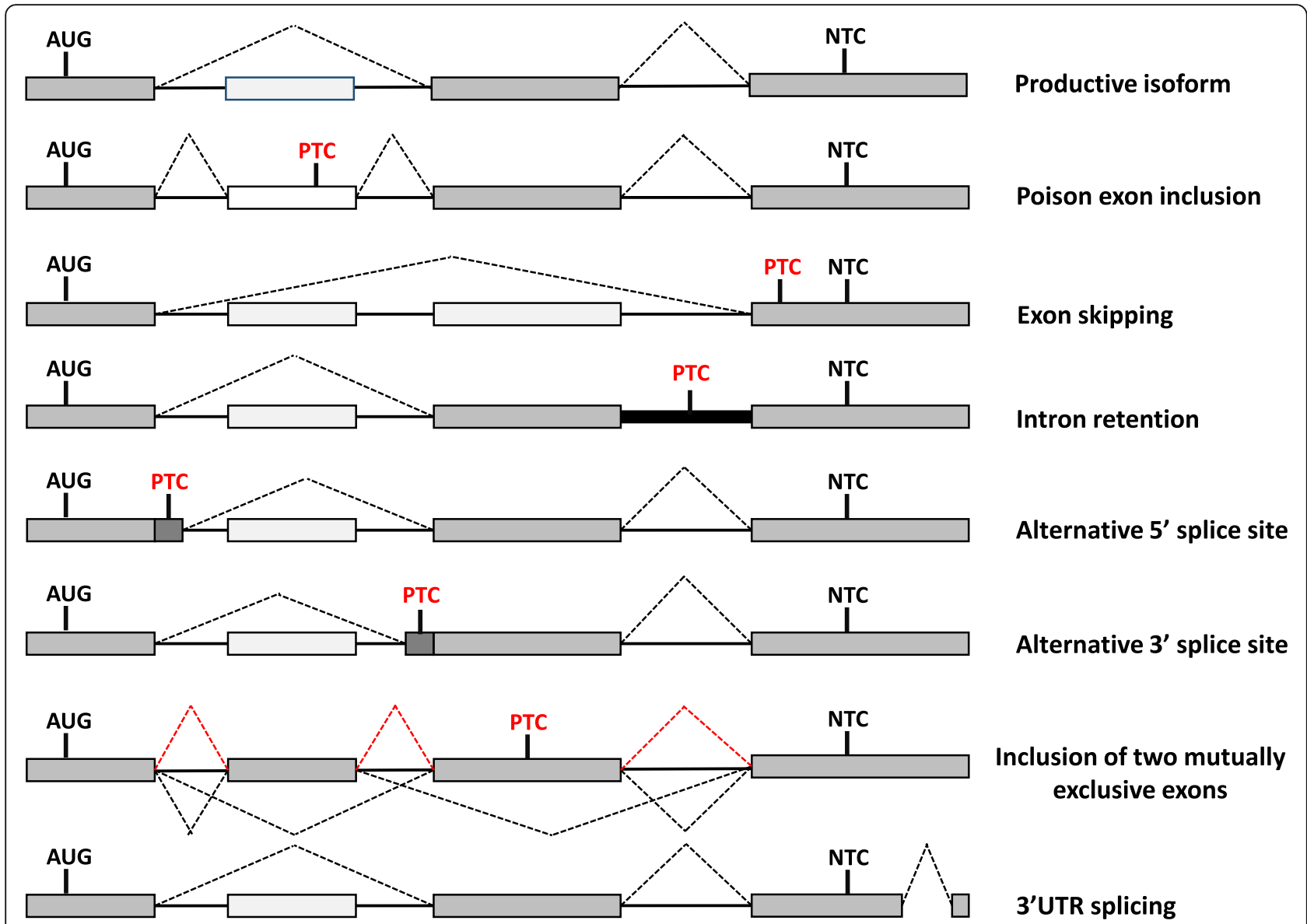

Fig. 2 Schematic representation of alternative splicing (AS) patterns inducing nonsense-mediated mRNA decay (NMD)-sensitive mRNA isoforms. The first mRNA isoform represents a productive transcript that encodes a functional protein. The following isoforms represent NMD-sensitive transcripts promoted by different AS patterns. Poison cassette inclusion leads to the retention of a premature translation-termination codon (PTC)-containing exon, while exon skipping can induce a frameshift in the mRNA sequence, introducing a downstream PTC. On the other hand, intron retention and alternative $5^{\prime} / 3^{\prime}$ splice sites may promote an NMD-target by including an in-frame PTC. Inclusion of two exons that usually are spliced separately may result in a frameshift, creating a PTC-positive isoform. The last isoform represents an AS pattern that leads to skipping in the $3^{\prime}$ untranslated region (3'UTR), which results in the presence of an exon junction complex downstream of the normal termination codon, favoring a premature context. AUG: start codon; NTC: normal termination codon

structured $\beta$-globin, can be induced by the presence of nonsense mutations in the $\beta$-globin gene $[6,7]$. In this situation, the mutated allele is recognized and degraded by NMD, thus preventing the formation of a truncated peptide product with potentially toxic effects to the cell $[6,7]$. This way, a heterozygous carrier of such mutation can still depend on the normally functioning wild type allele. However, there are cases where the PTC context does not trigger NMD leading to a dominant phenotype $[6,7]$. Other examples of this relationship include susceptibility to mycobacterial infection [136, 137], von Willebrand disease [138], factor X deficiency [139], retinitis pigmentosa and blindness $[140,141]$ and pseudoxanthoma elasticum [142]. In contrast, there are genetic disorders where truncated peptides may retain function and induce mild disease phenotypes. However, in these disorders, the NMD pathway acts to worsen the disease phenotype by degrading NMD-sensitive transcripts that would express partially-functional proteins. This type of phenotype modulation has been reported in diseases such as Duchenne muscular dystrophy, cystic fibrosis $[143,144]$, and spinal muscular atrophy [145].

While in most of the above-mentioned genetic diseases the quality-control facet of NMD is particularly relevant, different aspects of NMD activity have been explored by cancer cells to potentiate the disease [139]. Indeed, in normal circumstances, NMD has a protective role against cancer [26], acting as a tumor suppressor pathway through the downregulation of proteins involved in cell growth, cell cycle, apoptosis and cell 
migration [26]. However, some studies reported that tumor cells found ways to take advantage of NMD functions to potentiate the development of the disease [2]. In some cases, tumors may benefit from NMDmediated degradative activity by selecting the acquisition of PTCs in tumor-suppressor genes that allow the growth of tumor cells [20-25]. Other tumors arise from NMD impairment either by mutations in NMD factors or its stress-mediated inhibition [2, 26-28, 107, 146-150]. In the following sections we will discuss deeper the complexity of this relation between NMD and cancer.

\section{The complex role of NMD in cancer}

Tumors have found ways to leverage their unconstrained growth and the progression of cancer by taking advantage of both functions of NMD. On one hand, cancer cells use NMD activity to selectively downregulate tumor-suppressive genes through PTC acquisition, but on the other hand, these cells fine-tune NMD magnitude to allow the upregulation of stress-corrective genes responsible for their adaptation to the tumor microenvironment $[21,26]$. Although apparently straightforward, the role of NMD in cancer development and progression can, in fact, be quite complex [2, 26, 148, 149]. While in some contexts NMD may work as a tumor-suppressive pathway, in other scenarios its activity might aggravate the disease, depending on the genetic evolutionary history of the tumor $[2,151]$.

\section{NMD activity against tumorigenesis}

Disabling mutations in genes encoding NMD factors have been found in several types of cancers, which raised the possibility of NMD having some type of protective role against tumorigenesis. For instance, in pancreatic adenosquamous carcinoma (ASC) tumors and in lung inflammatory myofibroblastic tumors (IMTs), UPF1 gene exhibits splicing-altering mutations that compromise NMD activity $[27,28]$. This may lead to the upregulation of genes typically controlled by NMD that, therefore, contribute for the disease phenotype. For example, the NMD target encoding the mitogen activated protein kinase kinase kinase 14 (MAP 3 K14 or NIK), a potent activator of the proinflammatory nuclear factorkappa B (NF-kB) signaling pathway, is upregulated in the UPF1-mutated IMTs, promoting chemokine production and immune infiltrations that characterize this type of tumors [28]. Similarly, lung adenocarcinomas (ADCs) and hepatocellular carcinomas (HCCs) display lower expression of UPF1 when compared to normal tissues due to promoter hypermethylation, a finding that correlates with poor prognosis in patients with HCC [147, 152]. The resultant impairment of the NMD pathway leads to the upregulation of factors from the transforming growth factor beta (TGF- $\beta$ ) signaling pathway, which drive epithelial-mesenchymal transition (EMT) and, consequently, tumorigenesis and neoplasm metastasis [147]. In line with these clinical findings, there is experimental data showing that overexpression of UPF1 reduces the number and size of cultured tumor cell colonies when compared to control cells of several cancer cell lines [26]. Also, UPF1-overexpressing prostate cancer (PC3) cells injected as tumor explants in nude mice present no significant tumor growth [26]. Interestingly, an expression array analysis performed in human bone osteosarcoma (U2OS) cells subjected to NMD inhibition revealed that NMD controls the expression of a wide variety of transcripts that encode important factors involved in tumorigenesis-related processes, including cell growth, cell cycle, growth factor signaling, apoptosis and cell migration [26]. Altogether, it seems that typically NMD works as a tumor suppressor pathway by regulating the expression of genes involved in cell proliferation, differentiation and survival, and that tumors with impaired NMD, like the ones with mutated UPF1, have favorable conditions for tumor proliferation (Fig. 3a). Further supporting this idea is a study reporting that UPF3A, a paralog of UPF3B that inhibits NMD by sequestering UPF2 [47], is highly expressed in metastatic tissues of colorectal cancer (CRC) when compared to primary tissues [153]. This higher expression is associated with liver metastasis, recurrence and poor prognosis in CRC patients [153]. This finding was also reported in a previous study in which the interaction of the oncogenic transcription factors, signal transducer and activator of transcription 3 (STAT3), glioma oncogene homolog 1 (GLI1), and truncated GLI1 (tGLI1), was seen to promote UPF3A upregulation [154]. That higher UPF3A expression enhances the aggressiveness of triple-negative and human epidermal growth factor receptor 2 (HER2)enriched breast cancers and worsens metastasis free survival, according to the gene expression profile of breast tumors retrieved from the GEO database [154]. Thus, it is possible that some tumors with fully functional NMD factors may have found another way to control NMD activity by increasing the expression of modulators, like UPF3A, to leverage tumorigenesis and/or drive the disease (Fig. 3a).

In addition to its role in gene expression regulation, NMD ability to degrade PTC-harboring transcripts may also be involved in the protection of cancer development. It was shown that tumor suppressor genes have a higher propensity to acquire nonsense mutations than oncogenes, which present mostly missense mutations [19]. Moreover, many of these nonsense mutations are predicted to induce NMD [19]. Indeed, several tumor suppressor genes were found to present PTC- 


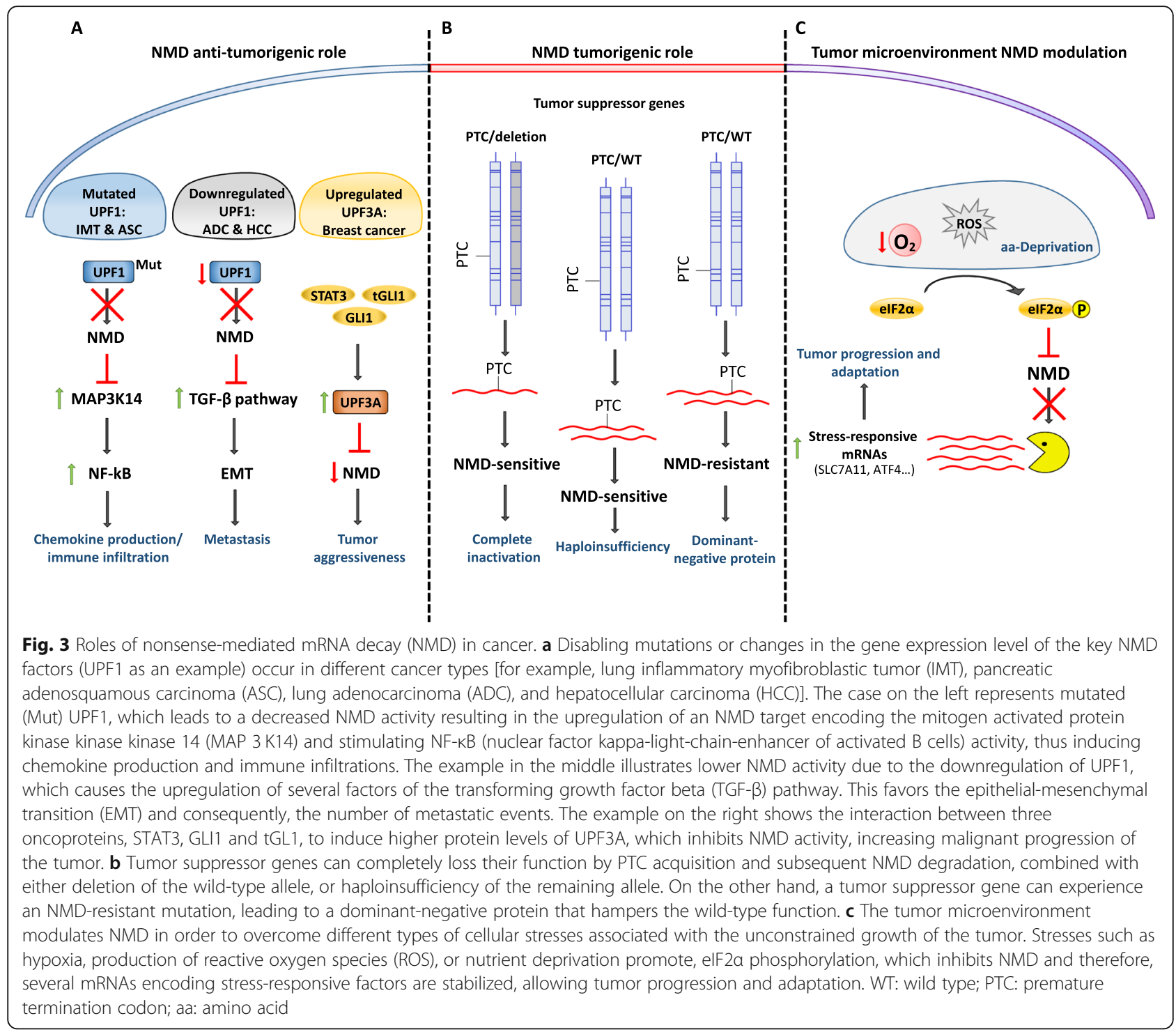

introducing mutations in a plethora of cancers, like p53 in mantle-cell lymphoma [23] and breast cancers [20], E-cadherin (CDH1) gene in hereditary diffuse gastric cancers (HDGC) [155], retinoblastoma 1 (RB1) gene in mantle-cell lymphoma [23], breast cancer type 1 susceptibility protein (BRCA1) gene in breast and ovarian cancers [22], and breast cancer type 2 susceptibility protein (BRCA2) gene in breast cancers [25]. Interestingly, the abnormal transcripts that result from these mutated tumor suppressor genes are stabilized in conditions of inhibited NMD, suggesting that this pathway is usually responsible for degrading them [20, 22, 23, 25, 155]. Therefore, in these contexts, the quality-control function of NMD may protect the cell from production of potential dominant-negative proteins that would, otherwise, lead to tumorigenesis, as has been described in different models, like BRCA1 in nude mice [156], p53 in human samples [27], or the Wilms' tumor protein 1 (WT1) gene in in vitro studies [24].

\section{NMD activity in cancer development and progression}

Despite the clear notion that NMD can work against cancer, in some contexts its activity may have the opposite effect. For instance, it was recently reported that NMD inhibition in CRCs with microsatellite instability (MSI) leads to decreased tumor growth in xenograft models, suggesting that NMD typically plays a protumorigenic role in these tumors [157]. Indeed, CRCs with MSI present a higher expression of UPF1, UPF2, SMG1, SMG6, and SMG7, when compared to the 
counterparts CRCs with microsatellite stability. The overexpression of NMD factors is thought to potentiate degradation of the increased number of potentially toxic PTC-bearing transcripts that MSI CRCs characteristically produce, promoting their survival [157]. In a different context, if a PTC-harboring tumor suppressor gene encodes a truncated protein that totally- or partiallypreserves its original function, rather than a dominantnegative one like described above, the targeted degradation of its mRNA by NMD could promote cancer development. Accordingly, patients with NMDsensitive mutations in $\mathrm{CDH} 1$ present a higher risk of developing HDGC than patients with NMD-resistant mutations, possibly because the latter produce truncated but still functional forms of E-cadherin [155]. Interestingly, in a study matching exome and transcriptome data from human tumors it was reported that nonsense mutations are enriched in regions of tumor suppressor genes expected to induce NMD [21]. As these mutations usually occur in heterozygosity [19], this raises the question of how NMD potentiates cancer development when at least one allele of a tumor suppressor is functional [158]. Regarding this, Lindeboom et al. have revealed that cancer cells take advantage of NMD activity to accomplish complete tumor suppressor inactivation, which can occur by three mechanisms: i) tumor selection for NMD-inducing mutations in one allele combined with a deletion in the second allele, thus achieving biallelic inactivation by a "two-hit" process; ii) selection for NMDinducing mutations in haploinsufficient versions of the wild-type allele, to eliminate residual function; and less frequently, iii) selection for NMD-resistant mutations in alleles that produce dominant-negative proteins [21] (Fig. 3b).

In addition to participating in the process of cancer development, NMD activity also seems to impact tumor evolution. During cancer progression, tumor cells acquire several somatic mutations that may, or not, favor the tumorigenic process. This is accompanied by a positive and negative selection that allows the proliferation of subclones with favorable mutations, such as PTCs in tumor suppressor genes or NMD-resistant/missense mutations in oncogenes, while eliminating the ones bearing detrimental mutations. By this means, cancer cells take advantage of NMD activity and of the rules that govern its induction to favor proliferation of transformed cells overproducing oncoproteins and other pro-tumorigenic proteins, thus driving further and aggravating the disease $[19,21]$.

\section{A role for AS-NMD in cancer}

As explained before, NMD activity is intimately linked to AS, together forming a key post-transcriptional mechanism of gene expression regulation. During the last decade, many dysregulated AS events have been observed in several cancer types, typically involving mutated splicing factors that lead to genome-wide altered patterns of gene expression. This can result in the production of NMD-sensitive isoforms of oncogenes and tumor suppressor genes that will, therefore, contribute for cancer development. A well-documented example is the SR protein, SRSF2, frequently mutated in patients with acute myeloid leukemia (AML) [159, 160]. A recent study reported that Pro95 hot spot mutation in SRSF2 enhances the stabilization of EJCs downstream from the PTC, thus favoring the association of key NMD factors to elicit NMD [159]. A robust target of SRSF2Mut is EZH2, which encodes a protein that catalyzes histone methylation and acts as tumor suppressor in myeloid malignancies [161]. SRSF2Mut drives the inclusion of a poison exon in the EZH2 pre-mRNA that triggers NMD and consequently shuts down its protein expression [159]. In agreement with this finding, there are studies reporting EZH2 loss-of function mutations in the same spectrum of myeloid disorders displaying mutated SRSF2 $[162,163]$. These data suggest that Pro95 mutation turns SRSF2 into an oncoprotein that uses AS-NMD to shut down the expression of a tumor-suppressor gene.

Epithelial cadherin (E-cadherin) is a crucial factor to maintain tissue integrity and polarization of epithelial cell layers and it is well-known that E-cadherin loss is a key event during cancer progression that contributes to the epithelial-mesenchymal transition [164]. Interestingly, Matos et al. discovered that one of the causes leading to E-cadherin decrease is an mRNA variant produced by AS that is committed to NMD [165]. That novel isoform arises from the usage of an alternative 3' splice site that ends in the depletion of 34 nucleotides in the exon 14, introducing a PTC. Moreover, stable breast cancer MCF7 cells expressing this novel variant resulted in a concomitant decrease of the wild type E-cadherin mRNA levels and higher cell migration and invasiveness [165]. However, it has to be elucidated the mechanism by which AS promotes this alternative isoform. Another example of an AS-NMD event impacting EMT is the one orchestrated by SRSF1. This splicing factor promotes a constitutively active isoform of the protooncogene MST1R ((Macrophage Stimulating 1 Receptor), by inducing skipping of exon 11 [166]. Consequently, the active isoform of MST1R induces EMT, as well as increases resistance to apoptosis [167-169]. ASNMD operates upstream in this pathway, inducing 3'UTR intron retention in SRSF1 under physiological conditions, which creates a stop codon premature context inducing NMD. However, in a tumorigenic context, another splicing factor, KHDRBS1 (KH RNA Binding Domain Containing, Signal Transduction Associated 1), 
stabilizes SRSF1 mRNA, which turns into a positive regulation of constitutive active MST1R.

Hypoxia is a major feature in solid tumors, given the high proliferating mass of cancer cells encountering an avascular environment that limits oxygen supply [170]. Interestingly, hypoxia seems to impact AS-NMD, as observed for the cysteine-rich angiogenic inducer 61 (CYR61), a matricellular protein that promotes cell proliferation, migration and angiogenesis in numerous solid tumors [171-173]. Under normal conditions, CYR61 experiences retention of intron 3 , which translates into a downstream PTC, leading to an NMD-sensitive isoform [174]. Nevertheless, hypoxic conditions alter this ASNMD gene regulation, inducing skipping of intron 3, which makes the transcript resistant to degradation by NMD.

$\mathrm{N}^{6}$-Methyladenosine $\left(\mathrm{m}^{6} \mathrm{~A}\right)$ RNA methylation is a common mRNA modification dynamically regulated in mammalian cells [175] that controls several steps of the mRNA metabolism, from mRNA processing and transport to translation or decay [176-179]. METTL3, the catalytic subunit of the $\mathrm{m}^{6} \mathrm{~A}$ methyltransferase complex, plays a critical role on tumorigenesis, promoting cell proliferation, survival, and invasion of cancer cells [180182]. Interestingly, $\mathrm{Li}$ et al. recently discovered that METTL3 modulates alternative splicing of splicing factors affecting the pool of PTC-bearing isoforms in glioblastoma cells [183]. Transcriptome studies showed that impaired METTL3 methylation results in the generation of PTCs in the mRNAs of several SRSFs, contrary to the existing scenario in malignant gliomas, which are associated with elevated expression of METTL3 and lower expression levels of SRSFs NMD spliced forms [183]. Moreover, authors demonstrated that oncogenicity derived from METTL3 activity is due to changes in alternative splicing events of genes with relevant implications in cancer cell death and migration, like $B C L-X$ and NCOR2. Altogether, this clearly indicates that dysregulated AS events in cancer cells contribute for the involvement of NMD in cancer development and/or progression.

\section{NMD modulation in the tumor microenvironment}

In striking contrast with the previous examples in which NMD promotes cancer is the finding that the tumor microenvironment induces NMD attenuation to potentiate cancer progression and adaptation, stressing out the idea that NMD activity has paradoxical outcomes. As mentioned above, during the unconstrained growth of the tumor, the blood supply to cancer cells becomes insufficient, creating a cellular environment of hypoxia, nutrient deprivation, production of ROS and ER stress, all stimuli that promote phosphorylation of eIF2 $\alpha$ and inhibit NMD [26, 105, 107, 109, 148] (Fig. 3c).
Accordingly, it has been reported that cancer cells grown as three-dimensional tumor explants present decreased NMD activity when compared to cancer cells cultured in monolayers, displaying significant levels of eIF2 $\alpha-P$ [26]. In fact, several studies showed increased levels of eIF2 $\alpha-\mathrm{P}$ in a plethora of cancers, including bronchioloalveolar, gastrointestinal and thyroid carcinomas, Hodgkin's lymphoma, melanocytic and colonic epithelial neoplasms, and breast cancer [184-189]. The downside effect of this stress-mediated NMD inhibition in tumors is the stabilization and upregulation of several transcripts encoding stress-responsive factors, which will help cancer cells to proliferate in the adverse environment of the tumor [26] (Fig. 3c). For instance, it has been reported that NMD inhibition by stress stabilizes the mRNA of the cystine/glutamate antiporter $\mathrm{xCT}$ [Solute Carrier Family 7 Member 11 (SLC7A11)], a subunit of the $\mathrm{xCT}$ amino acid transporter system. This ratelimiting channel is responsible for the uptake of cystine for production of the cellular antioxidant, glutathione (GSH), a tripeptide that neutralizes free radicals and reactive oxygen compounds. Curiously, it was shown that UPF1-depleted cells can survive to higher doses of $\mathrm{H} 2 \mathrm{O} 2$ in a SLC7A11-dependent manner, suggesting that NMD impairment during stress, and the consequent upregulation of SLC7A11, provides protection to cancer cells against the oxidative damage that may result from the overproduction of ROS [106]. The ATF4 mRNA is another NMD target frequently found to be upregulated in several types of solid tumors, consistent with NMD inhibition in these conditions $[190,191]$. Nutrient deprivation and oxidative stress promote ATF4 expression to transcriptionally induce genes involved in amino acid synthesis and transport, protein folding, cell differentiation, and autophagy, as a way to counterbalance the stress. Interestingly, it has been reported that the simultaneous molecular/pharmacological inhibition of autophagy and NMD leads to synergistic cell death in CRC cell lines, suggesting that autophagy is an adaptive response to NMD inhibition that allows cancer cells to overtake metabolic stress [192]. Moreover, ATF4 activity has been implicated in the chemo-resistance of CRC cells [190], further highlighting that NMD shut down by the tumor microenvironment can favor signaling cascades that potentiate tumor proliferation and malignancy. Altogether, these findings indicate that NMD impairment is a consequence and part of the adaptative mechanisms cancer cells use to thrive in the harmful microenvironment of the tumor.

\section{Using NMD modulation in cancer therapy}

The fact that NMD can both act as a tumor suppressor and a tumor promoter pathway depending on the genetic context of the cancer, imposes a challenge when it 
comes to using it in cancer therapy. NMD inhibition therapy can favor patients with tumors displaying PTCs in tumor suppressor genes encoding partially or fully functional proteins. However, this is not the case of tumors displaying a stress-adaptative gene expression pattern, in which NMD activation therapy would be more adequate. Nevertheless, global or gene-specific NMD modulation has great potential to be used in cancer therapy, being intensively studied with some very promising results.

\section{NMD activation in cancer therapy}

As above referred, some cancer types would benefit from a therapy based on NMD activation. This could be achieved by NMD-activating small molecules, with clinical utility to treat cancers in which the tumor-suppressive functions of NMD are beneficial, including solid tumors adapted to their own stressful microenvironment (Fig. 4a) [2, 8]. Despite being a simple approach in theory, this type of compounds may be difficult to develop. An easier alternative would be the development of oligonucleotides designed to re-engage NMD of cancer- and/or stress-related transcripts (Fig. 4a) [2]. In line with this, Tano et al. reported that treatment of human breast cancer cells (MCF10A and MCF10CA1h) with an NMD-inducing Morpholino against the signal transducer and activator of transcription 3 (STAT3) significantly reduces expression of this oncogenic transcription factor [193]. Despite this treatment had no effect on aspects of tumor cell biology (cell growth, viability, migration, and invasion) in the studied models, it highlights the therapeutic potential of using oligonucleotides to promote NMD of specific transcripts. This approach, however, would not be enough for tumors with affected expression of NMD factors, like ASC, ADCs and HCCs. In these cases, gene

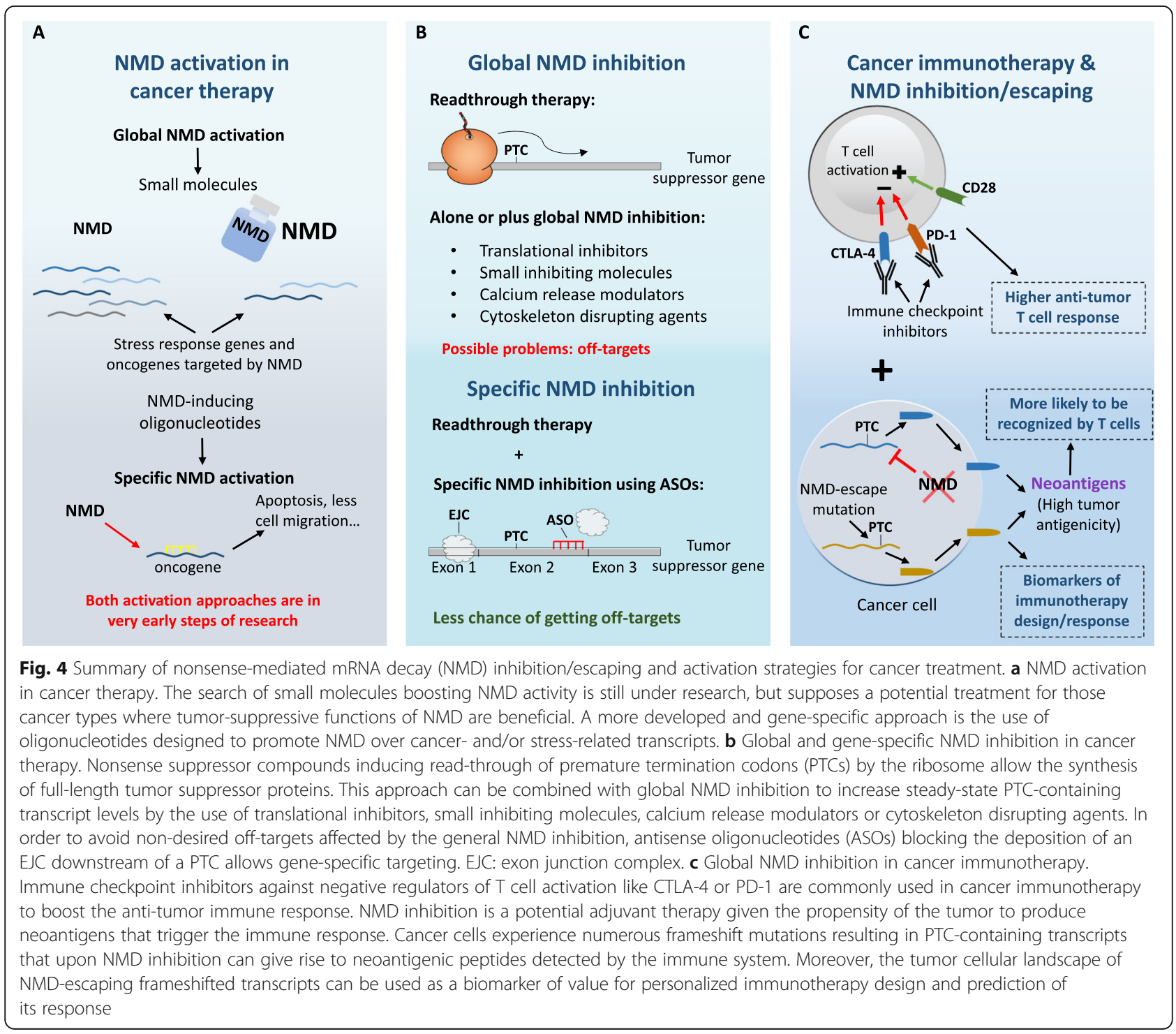


therapy aiming to induce expression of functional UPF1 could be of therapeutic value. To our knowledge, there are no studies so far directly testing this approach in the context of cancer. However, there are promising results in other diseases, like neurodegeneration. It was reported that transduced expression of human UPF1 in rat models of motor paralysis ameliorates the disease phenotype promoted by transactive response DNA-binding protein 43 $\mathrm{kDa}$ (TDP-43) [194]. Thus, the same results could be expected when applying this therapy to cancer models. Accordingly, gastric cancer cells (BGC-823 and SGC-7901) stably overexpressing UPF1 exhibit decreased cell proliferation, cell cycle progression, cell migration and invasion, and increased apoptosis, when compared to the control counterparts [195].

NMD activation therapy has the additional possibility of being used in combination with chemotherapy to protect normal cells from apoptosis [8]. This comes from the finding that chemotherapeutics promote NMD inhibition through caspase-mediated cleavage of UPF1 and UPF2, which creates truncated fragments with dominant-negative activity that leads to the upregulation of apoptosis-related NMD targets [196, 197]. Therefore, if it comes to be proven that NMD activation therapy increases normal cell survival, it will be possible to administer higher doses of chemotherapeutics to cancer patients to facilitate recovery after chemotherapy sessions [8]. Moreover, $\mathrm{Li}$ et al. reported that enforced expression of UPF1 can enhance sensitivity of BGC-823 and SGC-7901 cells to the chemotherapeutic, doxorubicin [195]. Thus, this therapeutic approach can potentially be used to increase the efficiency of chemotherapy itself.

Although NMD activation has great potential to be used in cancer therapy, the suggested approaches and methods are less developed than NMD inhibitory strategies. Therefore, there may be several years before being implemented in clinical practice.

\section{Global and gene-specific NMD inhibition in cancer therapy}

Nonsense suppressors represent a class of compounds that enhance the readthrough of PTCs by the translating ribosome [158]. Given this mechanism of action, these compounds can "silence" the quality control facet of NMD and promote the production of a full-length protein, providing interesting therapeutic applications (Fig. 4b). In fact, nonsense suppressors have already been tested not only in the context of cancer, but in other genetic diseases, like cystic fibrosis and Duchenne muscular dystrophy, with positive outcomes [198-200]. Specifically in cancer, readthrough therapy can induce the production of protective tumor suppressor proteins encoded by PTC-harboring transcripts, as was described for p53 [198]. Furthermore, in the discussed case of CRCs with MSI, it was reported that NMD inhibition with amlexanox, a presumed nonsense suppressor, reduces cell proliferation in MSI CRC HCT116 cells and has an antitumor effect on MSI tumor xenografts, possibly being an effective strategy for the personalized treatment of CRC with MSI [157]. Alternatively, there is a plethora of other molecules that can inhibit NMD in different ways and that could be used for cancer therapy. This includes translational inhibitors (that therefore will inhibit NMD), small inhibiting molecules, such as NMD inhibitor 1 (NMDI-1) that stabilizes hyperphosphorylated UPF1 and reduces the UPF1-SMG5 interactions [201], cardiac glycosides that increase cytoplasmic calcium [reported to inhibit NMD [202]], and cytoskeleton disrupting agents, which interfere with the transportation process of PTC-containing transcripts for degradation [203]. However, in most cases, this approach is only effective when combined with readthrough therapy, as most of these drugs would simply promote the stabilization of nonsense-mutated transcripts, not inducing production of the correspondent functional, full-length proteins. Accordingly, Martin et al. have identified several compounds capable of interfering with SMG7-UPF1 interaction that, when used in combination with a nonsense suppressor, could restore p53 fulllength protein and consequently promote the upregulation of p53 downstream transcripts, and cell death [204].

The usage of small inhibiting molecules/drugs to decrease NMD activity may present, however, a potential problem regarding their specificity, as these compounds might have off-targets that can compromise other cellular pathways or processes. This is aggravated by the fact that NMD targets several non-mutated transcripts, thus making it difficult to find the therapeutic dose of a global NMD inhibitor without having a major impact on the transcriptome. To overcome these issues, siRNAs and chemically modified antisense oligonucleotides (ASOs) designed to target NMD factors could provide a more specific therapeutic approach (Fig. 4b) [158]. Targeting NMD-substrates would be an even better alternative, because this would be expected to affect NMD of a single transcript. Accordingly, using ASOs to specifically block the deposition of an EJC downstream of a PTC could preclude its recognition by the NMD machinery. A practical example for this approach was recently provided by Rahman et al., who have showed, in HeLa cells, that the gene-specific blocking of EJC deposition using ASOs could avoid aberrant NMD of PTC-containing transcripts promoted by dysregulated AS events [159]. Nevertheless, once again, this type of therapy would only promote the stabilization of the PTC-containing mRNA, which could still encode a dominant-negative or nonfunctional protein. Therefore, this method would need 
to be combined with a readthrough compound to ultimately produce a functional full-length protein [158]. In line with this, Nomakuchi et al. have showed in vitro that the ASO-mediated NMD inhibition of a wellcharacterized NMD-substrate, the $\beta$-globin (HBB) gene with a nonsense mutation on codon 39 , used in combination with the readthrough compound, G418, could restore expression of the full-length HBB protein [205]. Thus, the gene-specific NMD inhibition combined with readthrough therapy represent a promising methodology to tackle tumors expressing dominant-negative or nonfunctional forms of tumor-suppressor proteins.

\section{Global NMD inhibition or escaping in cancer immunotherapy}

Early studies during the 90s in murine models revealed that $\mathrm{T}$ lymphocytes (or their effector molecules) are determinant to tumor control [206-208], suggesting a relationship between the organism's immune system and cancer. Very soon this idea was also observed in humans, in which clinical data supported a role for $\mathrm{T}$ lymphocytes in tumor immune surveillance. Accordingly, spontaneous regression of malignant melanomas was observed in the context of vitiligo (an autoimmune disease), and has been correlated with the presence of tumor-associated CD4+, activated T lymphocytes [209], and with an immune response to the tumor-associated antigen, melan-A/MART-1, mediated by specific cytotoxic lymphocytes [210]. This interaction between cancer and the immune system can be easily understood considering the highly mutagenic nature of many tumors: as mutations accumulate within cancer cells, several indels lead to the production of frameshifted transcripts encoding proteins that can act as neoantigens and trigger an immune response against the tumor [211]. In contrast, cancer cells have also exploited the natural immune checkpoint mechanisms (which normally act as fail-safes to prevent aberrant activation of the immune system and maintain immune homeostasis) to dampen anti-tumor $\mathrm{T}$ cell responses and prevent their immunity-mediated destruction [212]. This includes the expression of CD80/CD86 and PD-L1 ligands by the tumor [or the tumor-associated antigen-presenting cells (APCs)] that interact with the negative regulators of $\mathrm{T}$ cell activation, the CTLA- 4 and PD- 1 receptors, respectively, expressed at the membrane of the activated immune cells [reviewed in [212, 213]]. A better comprehension of the stimulatory and co-inhibitory immune mechanisms in the past few decades provided an opportunity to develop a new therapeutic approach to cancer, the immunotherapy. Cancer immunotherapy consists in the usage of immune checkpoint inhibitors that target CTLA-4, PD-1, and PD-L1, to activate or restore the immune system and counteract the resistance of cancer cells to the immune responses (Fig. 4c) [212]. The promising results obtained with these immune checkpoint inhibitors in cancer patients led the U.S. FDA to approve several drugs for numerous cancer treatments in recent years, as reviewed in [212].

Despite the therapeutic advantages provided by the immune checkpoint blockade therapy in cancer, its efficacy is highly variable and the response rates are usually below 40\% [212, 214, 215]. An important limitation might be the lack of a pre-existing anti-tumor immune response on which the checkpoint inhibitors can act [212]. In agreement with this, tumor biopsies revealed that melanoma regression following PD-1 blockade requires pre-existing $\mathrm{CD} 8+$, tumor-infiltrating $\mathrm{T}$ cells [216]. Similarly, an immune-active tumor microenvironment was reported to mediate the antitumor activity of CTLA-4 blockade [217]. Altogether, this stresses out the need to develop complementary therapeutic approaches to stimulate tumor-specific $\mathrm{T}$ cell responses and, thus, increase the efficacy of cancer immunotherapy.

As already mentioned, a key marker for immunotherapy response is the overall mutation burden of the tumor, i.e. the higher the number of accumulated frameshifting mutations, the greater the propensity of the tumor to produce neoantigenic peptides/proteins that can be detected by the immune system of the individual (Fig. 4c) [218]. Given that frameshift mutations usually result in PTC acquisition, Lindeboom et al. have recently hypothesized that NMD could also be involved in the efficacy of cancer immunotherapy [219]. Under lower pressure of the NMD pathway over PTC-harboring transcripts, there are more chances of producing neoantigens and therefore, higher immune infiltration. Indeed, after analysis of a pan-cancer cohort, the authors found that the burden of frameshift mutations that evade NMD correlates with increased tumor immune reactivity, suggesting a better response to immunotherapy [219]. Accordingly, Pastor and colleagues reported that the targeted inhibition of NMD in tumor cells leads to the expression of new antigens that are recognized and rejected by the immune system [220]. In fact, they showed that NMD inhibition in subcutaneous and metastatic tumor models leads to a significant reduction in tumor growth due to an enhanced tumor antigenicity. Therefore, NMD impairment, and the consequent preservation of PTC-harboring transcripts, seem to enhance the expression of neoantigens and the tumor response to immunotherapy [219, 220]. Given this, the described global NMD inhibitors have the potential to be used in a clinical context, either isolated or in combination with immune checkpoint inhibitors, for cancer immunotherapy [219]. These findings raised the possibility that the number of NMD-escaping frameshifting indels could be used as a biomarker of immunotherapy response (Fig. 
4c), in addition to the tumor mutation burden. Accordingly, Litchfield et al. showed that NMD-escaping frameshift mutated transcripts could help to predict response to immunotherapy in patients with low tumor mutation burden [221]. Moreover, in the study of Lindeboom et al., a model for classification of patients as responders to immunotherapy based on the tumor mutation burden and the NMD-escape frameshift mutation number provided a $5.86 \%$ increase in sensitivity over a model based only on the tumor mutation burden [219]. In the same line, very recent data from the combination of long-read and short-read cDNA sequencing have provided a cata$\log$ of full-length transcript species in a series of lung cancer cells. Based on this catalog, and considering the encoded full-length protein sequences, authors also identified potential neoantigens that can serve as predictive markers for immunotherapy [222]. Together, these data is of major importance, as not only NMD inhibition may be an effective strategy to improve responsiveness to cancer immunotherapy, but also the landscape of tumor frameshifted transcripts that escape NMD can be used to design personalized immunotherapy and predict its response.

\section{Conclusions}

The relationship between NMD and cancer is a complex one, where both its quality-control and regulatory functions can contribute to different stages of tumor development. Under normal circumstances, NMD is expected to have a protective role in the cell, preventing production of potential dominant-negative proteins and downregulating the expression of many important factors that can promote tumorigenesis [2, 26, 28, 107, 146-150]. However, growing evidence strongly suggests tumor cells may also be able to take advantage of such NMD functions to promote disease onset and progression. Indeed, one might view the role of NMD in cancer as a doublesided coin as it can act both as a tumor suppressor and a tumor promoter pathway depending on the genetic context of the cancer. Therefore, it seems of utmost importance to further explore the relevance of NMD in different cancer types and its exact mechanisms as this may set the ground for the development of novel therapeutic strategies. The development of such therapeutic strategies based on NMD modulation represents a challenge not only due to the complexity and specificity of the NMD-cancer relationship, but also due to the complexity of the disease itself. In addition, very recent data has revealed the potential of tumor frameshifted transcripts that escape NMD to encode neoatigens that can elicit immune response and function as markers for cancer immunotherapy design and prediction of its response.
Thus, it should be preconized the long-range sequencing of the tumor full-length transcriptome and the rules and effects of NMD should be incorporated into clinical decision-making processes, as, together, this information may better support personalized immunotherapy design.

\section{Abbreviations}

aa: Amino acid; ADCs: Lung adenocarcinomas; AML: Acute myeloid leukemia; APCs: Antigen presenting cells; AS: Alternative splicing; ASC: Adenosquamous carcinoma; ASOs: Antisense oligonucleotides; ATF: Activating transcription factor; BCL-X: B-cell lymphoma extra; BRCA: Breast cancer susceptibility protein; CCR4-NOT: Deadenylation complex; $\mathrm{CDH1}$ : Cadherin 1;

CRC: Colorectal cancer; CTLA-4: Cytotoxic T lymphocyte associated antigen 4; CYR61: Cysteine-rich angiogenic inducer 61; DCPC: Decapping complex; CHOP: CCAAT-enhancer-binding protein homologous protein; DECID: Decayinducing complex; DHX34: DEAH box polypeptide 34; elF: Eukaryotic initiation factor; EJC: Exon junction complex; EMT: Epithelial-mesenchymal transition; ER: Endoplasmic reticulum; eRF: Eukaryotic release factor; FDA: Food and Drug Administration; GADD45: Growth arrest and DNA damage 45; GAS5: Growth arrest specific 5; GLI1: Glioma oncogene homolog 1; GSH: Glutathione; HBB: Beta-globin; HCCs: Hepatocellular carcinomas; HDGC: Hereditary diffuse gastric cancers; HER2: Human epidermal growth factor receptor 2; hnRNPs: Heterogeneous nuclear ribonucleoproteins; IMTs: Inflammatory myofibroblastic tumors; ISR: Integrated stress response; KHDRBS1: KH RNA binding domain containing, signal transduction associated 1; MAP 3 K14: Mitogen activated protein kinase kinase kinase 14; MART1: Melanoma antigen recognized by T cells 1; METTL3: Methyltransferase like 3; MSI: Microsatellite instability; mRNA: Messenger RNA; NCOR2: Nuclear receptor corepressor 2; NF-kB: Nuclear factor-kappa B; NMD: Nonsensemediated RNA decay; NMDI-1: NMD inhibitor 1; nts: Nucleotides; PABPC1: Cytoplasmic poly(A)-binding protein 1; PAX3: Paired box gene 3; PC3: Prostate cancer; PD-1: Programmed cell death-1; PD-L1: Programmed death-ligand 1; PNRC2: Proline rich nuclear receptor coactivator 2; PP2A: Protein phosphatase 2A; PTBP1: Polypyrimidine tract-binding protein 1; PTCs: Premature termination codons; RB1: Retinoblastoma 1; RBP: RNAbinding protein; ROS: Reactive oxygen species; RSE: Stability element; SFV: Semliki forest virus; SINV: Sindbis virus; SLC7A11: Solute carrier family 7 member 11; SMD: Staufen-mediated decay; SR: Serine and arginine-rich; SRSF: Serine and arginine rich splicing factor; STAT3: Signal transducer and activator of transcription 3; TDP43: TAR (transactive response) DNA-binding protein 43; TGF- $\beta$ : Transforming growth factor beta; tGLI1: Truncated GLI1; UORF: Upstream open reading frames; UPF: Up-frameshift; UPR: Unfolded protein response; UTR: Untranslated region; WT1: Wilms' tumor protein 1; WT: Wild type

\section{Acknowledgements}

Not applicable.

\section{Authors' contributions}

Gonçalo Nogueira, Rafael Fernandes, and Juan Fernandez García-Moreno wrote and prepared the original draft; Luísa Romão supervised, reviewed and edited the manuscript. All authors have read and agreed to the published version of the manuscript.

\section{Funding}

Gonçalo Nogueira, Rafael Fernandes, and Juan Fernandez García-Moreno are recipients of a fellowship from BioSys PhD programme PD65-2012 (SFRH/PD/ BD/130959/2017, SFRH/BD/114392/2016 and SFRH/PD/BD/142898/2018, respectively) from FCT. This work was partially supported by UID/MULTI/04046/ 2019 Research Unit grant (to BiolSI).

Availability of data and materials Not applicable.

\section{Declarations}

Consent for publication Not applicable. 


\section{Competing interests}

The authors declare that they have no competing interests.

Received: 17 December 2020 Accepted: 19 April 2021 Published online: 29 April 2021

\section{References}

1. da Costa PJ, Menezes J, Romão L. The role of alternative splicing coupled to nonsense-mediated mRNA decay in human disease. Int J Biochem Cell Biol. 2017:91:168-75

2. Popp MW, Maquat LE. Nonsense-mediated mRNA decay and cancer. Curr Opin Genet Dev. 2018;48:44-50.

3. Lykke-Andersen $\mathrm{S}$, Jensen TH. Nonsense-mediated mRNA decay: an intricate machinery that shapes transcriptomes. Nat Rev Mol Cell Biol. 2015;16:665-77.

4. Popp MW-L, Maquat LE. Organizing principles of mammalian nonsensemediated mRNA decay. Annu Rev Genet. 2013;47:139-65.

5. Losson R, Lacroute F. Interference of nonsense mutations with eukaryotic messenger RNA stability. Proc Natl Acad Sci U S A. 1979;76:5134-7.

6. Maquat LE, Kinniburgh AJ, Rachmilewitz EA, Ross J. Unstable $\beta$-globin mRNA in mRNA-deficient $\beta^{\circ}$ thalassemia. Cell. 1981;27:543-53.

7. Miller JN, Pearce DA. Nonsense-mediated decay in genetic disease: friend or foe? Mutat Res Rev Mutat Res. 2014;762:52-64

8. Goetz AE, Wilkinson M. Stress and the nonsense-mediated RNA decay pathway. Cell Mol Life Sci. 2017;74:3509-31.

9. Tani H, Imamachi N, Salam KA, Mizutani R, ljiri K, Irie T, et al. Identification of hundreds of novel UPF1 target transcripts by direct determination of whole transcriptome stability. RNA Biol. 2012;9:1370-9.

10. Nguyen LS, Jolly L, Shoubridge C, Chan WK, Huang L, Laumonnier F, et al. Transcriptome profiling of UPF3B/NMD-deficient lymphoblastoid cells from patients with various forms of intellectual disability. Mol Psychiatry. 2012;17: 1103-15.

11. Weischenfeldt J, Damgaard I, Bryder D, Theilgaard-Monch K, Thoren LA, Nielsen FC, et al. NMD is essential for hematopoietic stem and progenitor cells and for eliminating by-products of programmed DNA rearrangements. Genes Dev. 2008;22:1381-96.

12. Chan W-K, Huang L, Gudikote JP, Chang Y-F, Imam JS, MacLean JA, et al. An alternative branch of the nonsense-mediated decay pathway. EMBO J. 2007; 26:1820-30.

13. Wittmann J, Hol EM, Jack H-M. hUPF2 silencing identifies physiologic substrates of mammalian nonsense-mediated mRNA decay. Mol Cell Biol. 2006;26:1272-87.

14. Mendell JT, Sharifi NA, Meyers JL, Martinez-Murillo F, Dietz HC. Nonsense surveillance regulates expression of diverse classes of mammalian transcripts and mutes genomic noise. Nat Genet. 2004;36:1073-8.

15. He F, Li X, Spatrick P, Casillo R, Dong S, Jacobson A. Genome-wide analysis of mRNAs regulated by the nonsense-mediated and $5^{\prime}$ to $3^{\prime}$ mRNA decay pathways in yeast. Mol Cell. 2003;12:1439-52.

16. Yepiskoposyan H, Aeschimann F, Nilsson D, Okoniewski M, Muhlemann O. Autoregulation of the nonsense-mediated mRNA decay pathway in human cells. RNA. 2011;17:2108-18.

17. Colombo M, Karousis ED, Bourquin J, Bruggmann R, Mühlemann O. Transcriptome-wide identification of NMD-targeted human mRNAs reveals extensive redundancy between SMG6- and SMG7-mediated degradation pathways. RNA. 2017:23:189-201.

18. Nasif S, Contu L, Mühlemann O. Beyond quality control: the role of nonsense-mediated mRNA decay (NMD) in regulating gene expression. Semin Cell Dev Biol. 2018;75:78-87.

19. Mort M, Ivanov D, Cooper DN, Chuzhanova NA. A meta-analysis of nonsense mutations causing human genetic disease. Hum Mutat. 2008;29: 1037-47.

20. Anczuków O, Ware MD, Buisson M, Zetoune AB, Stoppa-Lyonnet D, Sinilnikova OM, et al. Does the nonsense-mediated mRNA decay mechanism prevent the synthesis of truncated BRCA1, CHK2, and p53 proteins? Hum Mutat. 2008;29:65-73.

21. Lindeboom RGH, Supek $F$, Lehner $B$. The rules and impact of nonsensemediated mRNA decay in human cancers. Nat Genet. 2016;48:1112-8.

22. Perrin-Vidoz L, Sinilnikova OM, Stoppa-Lyonnet D, Lenoir GM, Mazoyer S. The nonsense-mediated mRNA decay pathway triggers degradation of most BRCA1 mRNAs bearing premature termination codons. Hum Mol Genet. 2002;11:2805-14.
23. Pinyol M, Bea S, Pla L, Ribrag V, Bosq J, Rosenwald A, et al. Inactivation of RB1 in mantle-cell lymphoma detected by nonsense-mediated mRNA decay pathway inhibition and microarray analysis. Blood. 2007;109:5422-9.

24. Reddy JC, Morris JC, Wang J, English MA, Haber DA, Shi Y, et al. WT1mediated transcriptional activation is inhibited by dominant negative mutant proteins. J Biol Chem. 1995;270:10878-84.

25. Ware MD, DeSilva D, Sinilnikova OM, Stoppa-Lyonnet D, Tavtigian SV, Mazoyer S. Does nonsense-mediated mRNA decay explain the ovarian cancer cluster region of the BRCA2 gene? Oncogene. 2006; 25:323-8.

26. Wang D, Zavadil J, Martin L, Parisi F, Friedman E, Levy D, et al. Inhibition of nonsense-mediated RNA decay by the tumor microenvironment promotes tumorigenesis. Mol Cell Biol. 2011:31:3670-80.

27. Liu C, Karam R, Zhou Y, Su F, Ji Y, Li G, et al. The UPF1 RNA surveillance gene is commonly mutated in pancreatic adenosquamous carcinoma. Nat Med. 2014;20:596-8.

28. Lu J, Plank T-D, Su F, Shi X, Liu C, Ji Y, et al. The nonsense-mediated RNA decay pathway is disrupted in inflammatory myofibroblastic tumors. J Clin Invest. 2016:126:3058-62.

29. Thermann R, Neu-Yilik G, Deters A, Frede U, Wehr K, Hagemeier C, et al. Binary specification of nonsense codons by splicing and cytoplasmic translation. EMBO J. 1998;17:3484-94.

30. Carter MS, Doskow J, Morris P, Li S, Nhim RP, Sandstedt S, et al. A regulatory mechanism that detects premature nonsense codons in T-cell receptor transcripts in vivo is reversed by protein synthesis inhibitors in vitro. J Biol Chem. 1995:270:28995-9003.

31. Metze S, Herzog VA, Ruepp M-D, Mühlemann O. Comparison of EJCenhanced and EJC-independent NMD in human cells reveals two partially redundant degradation pathways. RNA. 2013;19:1432-48.

32. Le Hir H, Izaurralde E, Izaurralde E. Maquat, Moore MJ. The spliceosome deposits multiple proteins 20\{textendash\}24 nucleotides upstream of mRNA exon-exon junctions. EMBO J. 2000;19:6860-9.

33. Le Hir H, Gatfield D, Izaurralde E, Moore MJ. The exon-exon junction complex provides a binding platform for factors involved in mRNA export and nonsense-mediated mRNA decay. EMBO J. 2001;20:4987-97.

34. Chan W, Huang L, Gudikote JP, Chang Y, Imam JS, MacLean JA, et al. An alternative branch of the nonsense-mediated decay pathway. EMBO J. 2007; 26:1820-30.

35. Alexandrov A, Colognori D, Shu M-D, Steitz JA. Human spliceosomal protein CWC22 plays a role in coupling splicing to exon junction complex deposition and nonsense-mediated decay. Proc Natl Acad Sci U S A. 2012 109:21313-8.

36. Ishigaki Y, Li X, Serin G, Maquat LE. Evidence for a pioneer round of mRNA translation. Cell. 2001;106:607-17.

37. Lejeune $F$, Ishigaki $Y$, Li X, Maquat LE. The exon junction complex is detected on CBP80-bound but not elF4E-bound mRNA in mammalian cells: dynamics of mRNP remodeling. EMBO J. 2002:21:3536-45.

38. Le Hir H, Izaurralde E, Maquat LE, Moore MJ. The spliceosome deposits multiple proteins 20-24 nucleotides upstream of mRNA exon-exon junctions. EMBO J. 2000;19:6860-9.

39. Gehring NH, Lamprinaki S, Kulozik AE, Hentze MW. Disassembly of exon junction complexes by PYM. Cell. 2009;137:536-48.

40. Stalder L, Mühlemann O. The meaning of nonsense. Trends Cell Biol. 2008; 18:315-21.

41. Maquat LE. Nonsense-mediated mRNA decay: splicing, translation and mRNP dynamics. Nat Rev Mol Cell Biol. 2004;5:89-99.

42. Kashima I, Yamashita A, Izumi N, Kataoka N, Morishita R, Hoshino S, et al. Binding of a novel SMG-1-Upf1-eRF1-eRF3 complex (SURF) to the exon junction complex triggers Upf1 phosphorylation and nonsense-mediated mRNA decay. Genes Dev. 2006:20:355-67.

43. Buchwald G, Ebert J, Basquin C, Sauliere J, Jayachandran U, Bono F, et al. Insights into the recruitment of the NMD machinery from the crystal structure of a core EJC-UPF3b complex. Proc Natl Acad Sci U S A. 2010;107: 10050-5.

44. Yamashita A, Izumi N, Kashima I, Ohnishi T, Saari B, Katsuhata Y, et al. SMG-8 and SMG-9, two novel subunits of the SMG-1 complex, regulate remodeling of the mRNA surveillance complex during nonsense-mediated mRNA decay. Genes Dev. 2009:23:1091-105.

45. Hug N, Cáceres JF. The RNA helicase DHX34 activates NMD by promoting a transition from the surveillance to the decay-inducing complex. Cell Rep. 2014;8:1845-56 
46. Melero R, Hug N, López-Perrote A, Yamashita A, Cáceres JF, Llorca O. The RNA helicase DHX34 functions as a scaffold for SMG1-mediated UPF1 phosphorylation. Nat Commun. 2016;7:10585.

47. Shum EY, Jones SH, Shao A, Dumdie J, Krause MD, Chan W-K, et al. The antagonistic gene paralogs Upf3a and Upf3b govern nonsense-mediated RNA decay. Cell. 2016;165:382-95.

48. Arias-Palomo E, Yamashita A, Fernández IS, Núñez-Ramírez R, Bamba Y, Izumi N, et al. The nonsense-mediated mRNA decay SMG-1 kinase is regulated by large-scale conformational changes controlled by SMG-8. Genes Dev. 2011;25:153-64.

49. Chamieh $\mathrm{H}$, Ballut $\mathrm{L}$, Bonneau F, Le Hir H. NMD factors UPF2 and UPF3 bridge UPF1 to the exon junction complex and stimulate its RNA helicase activity. Nat Struct Mol Biol. 2008;15:85-93.

50. Deniaud A, Karuppasamy M, Bock T, Masiulis S, Huard K, Garzoni F, et al. A network of SMG-8, SMG-9 and SMG-1 C-terminal insertion domain regulates UPF1 substrate recruitment and phosphorylation. Nucleic Acids Res. 2015; 43:7600-11.

51. Melero R, Uchiyama A, Castaño R, Kataoka N, Kurosawa H, Ohno S, et al. Structures of SMG1-UPFs complexes: SMG1 contributes to regulate UPF2dependent activation of UPF1 in NMD. Structure. 2014;22:1105-19.

52. Okada-Katsuhata Y, Yamashita A, Kutsuzawa K, Izumi N, Hirahara F, Ohno S. $\mathrm{N}$-and C-terminal Upf1 phosphorylations create binding platforms for SMG6 and SMG-5:SMG-7 during NMD. Nucleic Acids Res. 2012;40:1251-66.

53. Sun $X$, Maquat LE. mRNA surveillance in mammalian cells: the relationship between introns and translation termination. RNA. 2000;6:1-8.

54. Eberle AB, Stalder L, Mathys $H$, Orozco RZ, Mühlemann O. Posttranscriptional gene regulation by spatial rearrangement of the $3^{\prime}$ untranslated region. PLoS Biol. 2008;6:e92.

55. Ivanov PV, Gehring NH, Kunz JB, Hentze MW, Kulozik AE. Interactions between UPF1, eRFs, PABP and the exon junction complex suggest an integrated model for mammalian NMD pathways. EMBO J. 2008;27:736-47

56. Silva AL, Ribeiro $P$, Inácio Â, Liebhaber SA, Romão L. Proximity of the poly (a)-binding protein to a premature termination codon inhibits mammalian nonsense-mediated mRNA decay. RNA. 2008;14:563-76.

57. Singh G, Rebbapragada I, Lykke-Andersen J. A competition between stimulators and antagonists of Upf complex recruitment governs human nonsense-mediated mRNA decay. PLoS Biol. 2008;6:e111.

58. Wang W, Czaplinski K, Rao Y, Peltz SW. The role of Upf proteins in modulating the translation read-through of nonsense-containing transcripts. EMBO J. 2001:20:880-90.

59. Kononenko AV, Mitkevich VA, Atkinson GC, Tenson T, Dubovaya VI, Frolova $L Y$, et al. GTP-dependent structural rearrangement of the eRF1:eRF3 complex and eRF3 sequence motifs essential for PABP binding. Nucleic Acids Res. 2010;38:548-58.

60. Silva AL, Pereira FJ, Morgado A, Kong J, Martins R, Faustino P, Liebhaber SA, Romão L. The canonical UPF1-dependent nonsense-mediated mRNA decay is inhibited in transcripts carrying a short open reading frame independent of sequence context. RNA. 2006;12:2160-70.

61. Fiorini F, Bagchi D, Le Hir H, Croquette V. Human Upf1 is a highly processive RNA helicase and translocase with RNP remodelling activities. Nat Commun. 2015;6:7581.

62. Cho H, Kim KM, Kim YK. Human proline-rich nuclear receptor coregulatory protein 2 mediates an interaction between mRNA surveillance machinery and decapping complex. Mol Cell. 2009;33:75-86.

63. Eberle AB, Lykke-Andersen S, Mühlemann $\mathrm{O}$, Jensen TH. SMG6 promotes endonucleolytic cleavage of nonsense mRNA in human cells. Nat Struct Mol Biol. 2009:16:49-55.

64. Huntzinger E, Kashima I, Fauser M, Sauliere J, Izaurralde E. SMG6 is the catalytic endonuclease that cleaves mRNAs containing nonsense codons in metazoan. RNA. 2008;14:2609-17.

65. Boehm V, Haberman N, Ottens F, Ule J, Gehring NH. 3' UTR length and messenger ribonucleoprotein composition determine endocleavage efficiencies at termination codons. Cell Rep. 2014:9:555-68.

66. Schmidt SA, Foley PL, Jeong DH, Rymarquis LA, Doyle F, Tenenbaum SA, et al. Identification of SMG6 cleavage sites and a preferred RNA cleavage motif by global analysis of endogenous NMD targets in human cells. Nucleic Acids Res. 2015;43:309-23.

67. Lykke-Andersen S, Chen Y, Ardal BR, Lilje B, Waage J, Sandelin A, et al. Human nonsense-mediated RNA decay initiates widely by endonucleolysis and targets snoRNA host genes. Genes Dev. 2014;28:2498.
68. Fukuhara N, Ebert J, Unterholzner L, Lindner D, Izaurralde E, Conti E. SMG7 is a 14-3-3-like adaptor in the nonsense-mediated mRNA decay pathway. Mol Cell. 2005;17:537-47.

69. Gatfield D, Izaurralde E. Nonsense-mediated messenger RNA decay is initiated by endonucleolytic cleavage in drosophila. Nature. 2004;429:575-8.

70. Lejeune F, Li X, Maquat LE. Nonsense-mediated mRNA decay in mammalian cells involves decapping, deadenylating, and exonucleolytic activities. Mol Cell. 2003;12:675-87.

71. Unterholzner L, Izaurralde E. SMG7 acts as a molecular link between mRNA surveillance and mRNA decay. Mol Cell. 2004;16:587-96.

72. Neu-Yilik G, Raimondeau E, Eliseev B, Yeramala L, Amthor B, Deniaud A, et al. Dual function of UPF3B in early and late translation termination. EMBO J. 2017:36:2968-86.

73. Mühlemann $\mathrm{O}$, Karousis ED. New functions in translation termination uncovered for NMD factor UPF3B. EMBO J. 2017:36:2928-30.

74. Gehring NH, Kunz JB, Neu-Yilik G, Breit S, Viegas MH, Hentze MW, et al. Exon-junction complex components specify distinct routes of nonsensemediated mRNA decay with differential cofactor requirements. Mol Cell. 2005;20:65-75.

75. Bühler M, Steiner S, Mohn F, Paillusson A, Mühlemann O. EJC-independent degradation of nonsense immunoglobulin- $\mu$ mRNA depends on 3' UTR length. Nat Struct Mol Biol. 2006;13:462-4.

76. Huang L, Lou C-H, Chan W, Shum EY, Shao A, Stone E, et al. RNA homeostasis governed by cell type-specific and branched feedback loops acting on NMD. Mol Cell. 2011;43:950-61.

77. Aznarez I, Nomakuchi TT, Tetenbaum-Novatt J, Rahman MA, Fregoso O, Rees $\mathrm{H}$, et al. Mechanism of nonsense-mediated mRNA decay stimulation by splicing factor SRSF1. Cell Rep. 2018;23:2186-98.

78. Chan W-K, Bhalla AD, Le Hir H, Nguyen LS, Huang L, Gécz J, et al. A UPF3mediated regulatory switch that maintains RNA surveillance. Nat Struct Mol Biol. 2009;16:747-53.

79. Lelivelt MJ, Culbertson MR. Yeast Upf proteins required for RNA surveillance affect global expression of the yeast transcriptome. Mol Cell Biol. 1999;19:6710-9.

80. Mühlemann O. Recognition of nonsense mRNA: towards a unified model. Biochem Soc Trans. 2008:36:497-501.

81. Bin SA, Wilkinson MF, Van Hoof A. Messenger RNA regulation: to translate or to degrade. EMBO J. 2008;27:471-81.

82. Silva $A L$, Romão $L$. The mammalian nonsense-mediated mRNA decay pathway: to decay or not to decay! Which players make the decision? FEBS Lett. 2009:583:499-505.

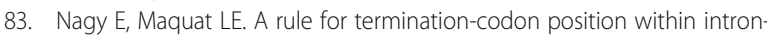
containing genes: when nonsense affects RNA abundance. Trends Biochem Sci. 1998;23:198-9.

84. Oliveira CC, McCarthy JE. The relationship between eukaryotic translation and mRNA stability. A short upstream open reading frame strongly inhibits translational initiation and greatly accelerates mRNA degradation in the yeast Saccharomyces cerevisiae. J Biol Chem. 1995;270:8936-43.

85. Hoek TA, Khuperkar D, Lindeboom RGH, Sonneveld S, Verhagen BMP, Boersma S, et al. Single-molecule imaging uncovers rules governing nonsense-mediated mRNA decay. Mol Cell. 2019;75:324-339.e11.

86. Medghalchi SM, Frischmeyer PA, Mendell JT, Kelly AG, Lawler AM, Dietz HC. Rent1, a trans-effector of nonsense-mediated mRNA decay, is essential for mammalian embryonic viability. Hum Mol Genet. 2001;10:99-105.

87. Li T, Shi Y, Wang P, Guachalla LM, Sun B, Joerss T, et al. Smg6/Est1 licenses embryonic stem cell differentiation via nonsense-mediated mRNA decay. EMBO J. 2015;34:1630-47.

88. Mcllwain DR, Pan Q, Reilly PT, Elia AJ, McCracken S, Wakeham AC, et al. Smg1 is required for embryogenesis and regulates diverse genes via alternative splicing coupled to nonsense-mediated mRNA decay. Proc Natl Acad Sci U S A. 2010;107:12186-91.

89. Shaheen R, Anazi S, Ben-Omran T, Seidahmed MZ, Caddle LB, Palmer K, et al. Mutations in SMG9, encoding an essential component of nonsensemediated decay machinery, cause a multiple congenital anomaly syndrome in humans and mice. Am J Hum Genet. 2016;98:643-52.

90. Nelson JO, Moore KA, Chapin A, Hollien J, Metzstein MM. Degradation of GADD45 mRNA by nonsense-mediated decay is essential for viability. Elife. 2016;5:e12876.

91. Tani $\mathrm{H}$, Torimura M, Akimitsu N. The RNA degradation pathway regulates the function of GAS5 a non-coding RNA in mammalian cells. PLoS One. 2013;8:e55684. 
92. Mourtada-Maarabouni M, Williams GT. Growth arrest on inhibition of nonsense-mediated decay is mediated by noncoding RNA GAS5. Biomed Res Int. 2013;2013:358015.

93. Thoren LA, Nørgaard GA, Weischenfeldt J, Waage J, Jakobsen JS, Damgaard I, et al. UPF2 is a critical regulator of liver development, function and regeneration. PLoS One. 2010;5:e11650.

94. Bao J, Tang C, Yuan S, Porse BT, Yan W. UPF2, a nonsense-mediated mRNA decay factor, is required for prepubertal Sertoli cell development and male fertility by ensuring fidelity of the transcriptome. Development. 2015;142: 352-62.

95. Bao J, Vitting-Seerup K, Waage J, Tang C, Ge Y, Porse BT, et al. UPF2dependent nonsense-mediated mRNA decay pathway is essential for spermatogenesis by selectively eliminating longer $3^{\prime} U T R$ transcripts. PLoS Genet. 2016;12:e1005863.

96. Turner JMA. Meiotic sex chromosome inactivation. Development. 2007;134: 1823-31.

97. Gong C, Kim YK, Woeller CF, Tang Y, Maquat LE. SMD and NMD are competitive pathways that contribute to myogenesis: effects on PAX3 and myogenin mRNAs. Genes Dev. 2009;23:54-66.

98. Kim YK, Furic L, Parisien M, Major F, DesGroseillers L, Maquat LE. Staufen 1 regulates diverse classes of mammalian transcripts. EMBO J. 2007;26:2670-81.

99. Lou CH, Shao A, Shum EY, Espinoza JL, Huang L, Karam R, et al. Posttranscriptional control of the stem cell and neurogenic programs by the nonsense-mediated RNA decay pathway. Cell Rep. 2014;6:748-64.

100. Bruno IG, Karam R, Huang L, Bhardwaj A, Lou CH, Shum EY, et al. Identification of a microRNA that activates gene expression by repressing nonsense-mediated RNA decay. Mol Cell. 2011:42:500-10.

101. Laumonnier F, Shoubridge C, Antar C, Nguyen LS, Van Esch H, Kleefstra T, et al. Mutations of the UPF3B gene, which encodes a protein widely expressed in neurons, are associated with nonspecific mental retardation with or without autism. Mol Psychiatry. 2010;15:767-76.

102. Tarpey PS, Lucy Raymond F, Nguyen LS, Rodriguez J, Hackett A, Vandeleur $L$, et al. Mutations in UPF3B, a member of the nonsense-mediated mRNA decay complex, cause syndromic and nonsyndromic mental retardation. Nat Genet. 2007:39:1127-33.

103. Nguyen LS, Kim H-G, Rosenfeld JA, Shen Y, Gusella JF, Lacassie Y, et al. Contribution of copy number variants involving nonsense-mediated mRNA decay pathway genes to neuro-developmental disorders. Hum Mol Genet. 2013;22:1816-25.

104. Karam R, Lou C-H, Kroeger H, Huang L, Lin JH, Wilkinson MF. The unfolded protein response is shaped by the NMD pathway. EMBO Rep. 2015:16:599-609.

105. Gardner LB. Hypoxic inhibition of nonsense-mediated RNA decay regulates gene expression and the integrated stress response. Mol Cell Biol. 2008;28: 3729-41.

106. Martin L, Gardner LB. Stress-induced inhibition of nonsense-mediated RNA decay regulates intracellular cystine transport and intracellular glutathione through regulation of the cystine/glutamate exchanger SLC7A11. Oncogene. 2015;34:4211-8.

107. Wang D, Wengrod J, Gardner LB. Overexpression of the c-myc oncogene inhibits nonsense-mediated RNA decay in B lymphocytes. J Biol Chem. 2011;286:40038-43.

108. Li Z, Vuong JK, Zhang M, Stork C, Zheng S. Inhibition of nonsense-mediated RNA decay by ER stress. RNA. 2017;23:378-94.

109. Karam R, Lou C-H, Kroeger H, Huang L, Lin JH, Wilkinson MF. The unfolded protein response is shaped by the NMD pathway. EMBO Rep. 2015;16:599-609.

110. Pakos-Zebrucka K, Koryga I, Mnich K, Ljujic M, Samali A, Gorman AM. The integrated stress response. EMBO Rep. 2016;17:1374-95.

111. Hetz $C$. The unfolded protein response: controlling cell fate decisions under ER stress and beyond. Nat Rev Mol Cell Biol. 2012;13:89-102.

112. Gordiyenko Y, Llácer JL, Ramakrishnan V. Structural basis for the inhibition of translation through elF2a phosphorylation. Nat Commun. 2019;10:1-11.

113. Oren YS, McClure ML, Rowe SM, Sorscher EJ, Bester AC, Manor M, et al. The unfolded protein response affects readthrough of premature termination codons. EMBO Mol Med. 2014;6:685-701.

114. Balistreri G, Horvath P, Schweingruber C, Zünd D, Mclnerney G, Merits A, et al. The host nonsense-mediated mRNA decay pathway restricts mammalian RNA virus replication. Cell Host Microbe. 2014;16:403-11.

115. Mocquet V, Neusiedler J, Rende F, Cluet D, Robin J-P, Terme J-M, et al. The human T-lymphotropic virus type 1 tax protein inhibits nonsense- mediated mRNA decay by interacting with INT6/EIF3E and UPF1. J Virol. 2012;86:7530-43.

116. Nakano K, Ando T, Yamagishi M, Yokoyama K, Ishida T, Ohsugi T, et al. Viral interference with host mRNA surveillance, the nonsense-mediated mRNA decay (NMD) pathway, through a new function of HTLV-1 Rex: implications for retroviral replication. Microbes Infect. 2013;15:491-505.

117. Lareau LF, Brooks AN, Soergel DAW, Meng Q, Brenner SE. The coupling of alternative splicing and nonsense-mediated mRNA decay. Adv Exp Med Biol. 2007;623:190-211.

118. García-Moreno JF, Romão L. Perspective in alternative splicing coupled to nonsense-mediated mRNA decay. Int J Mol Sci. 2020;21:1-21.

119. Graveley BR. Alternative splicing: increasing diversity in the proteomic world. Trends Genet. 2001:17:100-7.

120. Nilsen TW, Graveley BR. Expansion of the eukaryotic proteome by alternative splicing. Nature. 2010:463:457-63.

121. Kelemen $O$, Convertini $P$, Zhang Z, Wen $Y$, Shen M, Falaleeva M, et al. Function of alternative splicing. Gene. 2013;514:1-30.

122. Lewis BP, Green RE, Brenner SE. Evidence for the widespread coupling of alternative splicing and nonsense-mediated mRNA decay in humans. Proc Natl Acad Sci U S A. 2003;100:189-92.

123. Chang Y-F, Imam JS, Wilkinson MF. The nonsense-mediated decay RNA surveillance pathway. Annu Rev Biochem. 2007;76:51-74.

124. Ge Y, Porse BT. The functional consequences of intron retention: alternative splicing coupled to NMD as a regulator of gene expression. BioEssays. 2014; 36:236-43.

125. Lareau LF, Inada M, Green RE, Wengrod JC, Brenner SE. Unproductive splicing of SR genes associated with highly conserved and ultraconserved DNA elements. Nature. 2007:446:926-9.

126. Sureau A, Gattoni R, Dooghe Y, Stévenin J, Soret J. SC35 autoregulates its expression by promoting splicing events that destabilize its mRNAs. EMBO J. 2001;20:1785-96.

127. Wollerton MC, Gooding C, Wagner EJ, Garcia-Blanco MA, Smith CWJ. Autoregulation of polypyrimidine tract binding protein by alternative splicing leading to nonsense-mediated decay. Mol Cell. 2004;13:91-100.

128. Sun S, Zhang Z, Sinha R, Karni R, Krainer AR. SF2/ASF autoregulation involves multiple layers of post-transcriptional and translational control. Nat Struct Mol Biol. 2010;17:306-12.

129. Pervouchine D, Popov Y, Berry A, Borsari B, Frankish A, Guigó R. Integrative transcriptomic analysis suggests new autoregulatory splicing events coupled with nonsense-mediated mRNA decay. Nucleic Acids Res. 2019;47: 5293-306.

130. McGlincy NJ, Tan LY, Paul N, Zavolan M, Lilley KS, Smith CWJ. Expression proteomics of UPF1 knockdown in HeLa cells reveals autoregulation of hnRNP A2/B1 mediated by alternative splicing resulting in nonsensemediated mRNA decay. BMC Genomics. 2010;11:565.

131. Graveley BR. Sorting out the complexity of SR protein functions. RNA. 2000; 6:1197-211.

132. Lam BJ, Hertel KJ. A general role for splicing enhancers in exon definition. RNA. 2002:8:1233-41.

133. Saltzman AL, Kim YK, Pan Q, Fagnani MM, Maquat LE, Blencowe BJ. Regulation of multiple core spliceosomal proteins by alternative splicingcoupled nonsense-mediated mRNA decay. Mol Cell Biol. 2008;28:4320-30.

134. Mitrovich QM, Anderson P. Unproductively spliced ribosomal protein mRNAs are natural targets of mRNA surveillance in C. elegans. Genes Dev. 2000:14:2173-84.

135. Cuccurese M, Russo G, Russo A, Pietropaolo C. Alternative splicing and nonsense-mediated mRNA decay regulate mammalian ribosomal gene expression. Nucleic Acids Res. 2005;33:5965-77.

136. Jouanguy E, Lamhamedi-Cherradi S, Lammas D, Dorman SE, Fondanèche MC, Dupuis S, et al. A human IFNGR1 small deletion hotspot associated with dominant susceptibility to mycobacterial infection. Nat Genet. 1999;21: 370-8.

137. Jouanguy E, Altare F, Lamhamedi S, Revy P, Emile J-F, Newport M, et al. Interferon- $\gamma$-receptor deficiency in an infant with fatal bacille CalmetteGuérin infection. N Engl J Med. 1996;335:1956-62.

138. Schneppenheim R, Budde U, Obser T, Brassard J, Mainusch K, Ruggeri ZM, et al. Expression and characterization of von Willebrand factor dimerization defects in different types of von Willebrand disease. Blood. 2001;97:2059-66.

139. Millar DS, Elliston L, Deex P, Krawczak M, Wacey Al, Reynaud J, et al. Molecular analysis of the genotype-phenotype relationship in factor $X$ deficiency. Hum Genet. 2000;106:249-57. 
140. Rosenfeld PJ, Cowley GS, McGee TL, Sandberg MA, Berson EL, Dryja TP. A null mutation in the rhodopsin gene causes rod photoreceptor dysfunction and autosomal recessive retinitis pigmentosa. Nat Genet. 1992;1:209-13.

141. Sung CH, Davenport CM, Hennessey JC, Maumenee IH, Jacobson SG, Heckenlively JR, et al. Rhodopsin mutations in autosomal dominant retinitis pigmentosa. Proc Natl Acad Sci U S A. 1991;88:6481-5.

142. Plomp AS, Hu X, De Jong PTVM, Bergen AAB. Does autosomal dominant pseudoxanthoma elasticum exist? Am J Med Genet. 2004;126(A):403-12.

143. Rowe SM, Sloane P, Tang LP, Backer K, Mazur M, Buckley-Lanier J, et al. Suppression of CFTR premature termination codons and rescue of CFTR protein and function by the synthetic aminoglycoside NB54. J Mol Med. 2011:89:1149-61.

144. Howard M, Frizzell RA, Bedwell DM. Aminoglycoside antibiotics restore CFTR function by overcoming premature stop mutations. Nat Med. 1996;2:467-9.

145. Wolstencroft EC, Mattis V, Bajer AA, Young PJ, Lorson CL. A nonsequence-apecific requirement for SMN protein activity: the role of aminoglycosides in inducing elevated SMN protein levels. Hum Mol Genet. 2005;14:1199-210.

146. Gardner LB. Nonsense-mediated RNA decay regulation by cellular stress: implications for tumorigenesis. Mol Cancer Res. 2010;8:295-308.

147. Cao L, Qi L, Zhang L, Song W, Yu Y, Xu C, et al. Human nonsense-mediated RNA decay regulates EMT by targeting the TGF- $\beta$ signaling pathway in lung adenocarcinoma. Cancer Lett. 2017;403:246-59.

148. Giampietri C, Petrungaro S, Conti S, Facchiano A, Filippini A, Ziparo E. Cancer microenvironment and endoplasmic reticulum stress response mediators. Inflamm. 2015;2015:417281.

149. Degenhardt K, Mathew R, Beaudoin B, Bray K, Anderson D, Chen G, et al. Autophagy promotes tumor cell survival and restricts necrosis, inflammation, and tumorigenesis. Cancer Cell. 2006;10:51-64.

150. Ye J, Kumanova M, Hart LS, Sloane K, Zhang H, De Panis DN, et al. The GCN2-ATF4 pathway is critical for tumour cell survival and proliferation in response to nutrient deprivation. EMBO J. 2010;29:2082-96.

151. Fernandes R, Nogueira G, da Costa PJ, Pinto F, Romão L. Nonsensemediated mRNA decay in development, stress and cancer. In: Romão L, editor. Adv Exp med biol. Cham: Springer New York LLC; 2019. p. 41-83.

152. Chang L, Li C, Guo T, Wang H, Ma W, Yuan Y, et al. The human RNA surveillance factor UPF1 regulates tumorigenesis by targeting Smad7 in hepatocellular carcinoma. J Exp Clin Cancer Res. 2016;35:8.

153. Bao X, Huang $Y, X u$ W, Xiong G. Functions and clinical significance of UPF3A expression in human colorectal cancer. Cancer Manag Res. 2020;12: 4271-81.

154. Sirkisoon SR, Carpenter RL, Rimkus T, Anderson A, Harrison A, Lange AM, et al. Interaction between STAT3 and GLI1/tGLI1 oncogenic transcription factors promotes the aggressiveness of triple-negative breast cancers and HER2-enriched breast cancer. Oncogene. 2018;37:2502-14.

155. Karam R, Carvalho J, Bruno I, Graziadio C, Senz J, Huntsman D, et al. The NMD mRNA surveillance pathway downregulates aberrant E-cadherin transcripts in gastric cancer cells and in $\mathrm{CDH} 1$ mutation carriers. Oncogene. 2008;27:4255-60.

156. Fan S, Yuan RQ, Ma YX, Meng Q, Goldberg ID, Rosen EM. Mutant BRCA1 genes antagonize phenotype of wild-type BRCA1. Oncogene. 2001;20:821535.

157. Bokhari A, Jonchere $V$, Lagrange A, Bertrand R, Svrcek M, Marisa L, et al. Targeting nonsense-mediated mRNA decay in colorectal cancers with microsatellite instability. Oncogenesis. 2018;7:70.

158. Kurosaki T, Popp MW, Maquat LE. Quality and quantity control of gene expression by nonsense-mediated mRNA decay. Nat Rev Mol Cell Biol. 2019; 20:406-20.

159. Rahman MA, Lin KT, Bradley RK, Abdel-Wahab O, Krainer AR. Recurrent SRSF2 mutations in MDS affect both splicing and NMD. Genes Dev. 2020;34: 413-27.

160. Kim E, llagan JO, Liang Y, Daubner GM, Lee SCW, Ramakrishnan A, et al. SRSF2 mutations contribute to myelodysplasia by mutant-specific effects on exon recognition. Cancer Cell. 2015;27:617-30.

161. Ernst T, Chase AJ, Score J, Hidalgo-Curtis CE, Bryant C, Jones AV, et al. Inactivating mutations of the histone methyltransferase gene $\mathrm{EZH} 2$ in myeloid disorders. Nat Genet. 2010;42:722-6.

162. Nikoloski G, Langemeijer SMC, Kuiper RP, Knops R, Massop M, Tönnissen ERLTM, et al. Somatic mutations of the histone methyltransferase gene EZH2 in myelodysplastic syndromes. Nat Genet. 2010;42:665-7.
163. Sashida G, Harada H, Matsui H, Oshima M, Yui M, Harada Y, et al. Ezh2 loss promotes development of myelodysplastic syndrome but attenuates its predisposition to leukaemic transformation. Nat Commun. 2014;5:4177.

164. Yu W, Yang L, Li T, Zhang Y. Cadherin signaling in cancer: its functions and role as a therapeutic target. Front Oncol. 2019;9:989.

165. Matos ML, Lapyckyj L, Rosso M, Besso MJ, Mencucci MV, Briggiler CIM, et al. Identification of a novel human E-cadherin splice variant and assessment of its effects upon EMT-related events. J Cell Physiol. 2017;232:1368-86.

166. Ghigna C, Giordano S, Shen H, Benvenuto F, Castiglioni F, Comoglio PM, et al. Cell motility is controlled by SF2/ASF through alternative splicing of the RON protooncogene. Mol Cell. 2005;20:881-90.

167. Zhou YQ, He C, Chen YQ, Wang D, Wang MH. Altered expression of the $\mathrm{RON}$ receptor tyrosine kinase in primary human colorectal adenocarcinomas: generation of different splicing RON variants and their oncogenic potential. Oncogene. 2003;22:186-97.

168. Krishnaswamy S, Mohammed AK, Tripathi G, Alokail MS, Al-Daghri NM. Splice variants of the extracellular region of RON receptor tyrosine kinase in lung cancer cell lines identified by PCR and sequencing. BMC Cancer. 2017; 17:738.

169. Ling Y, Kuang Y, Chen LL, Lao WF, Zhu YR, Wang LQ, et al. A novel RON splice variant lacking exon 2 activates the PI3K AKT pathway via PTEN phosphorylation in colorectal carcinoma cells. Oncotarget. 2017;8:39101-16.

170. Brahimi-Horn MC, Chiche J, Pouysségur J. Hypoxia and cancer. J Mol Med. 2007:85:1301-7.

171. Chen Y, Du XY. Functional properties and intracellular signaling of CCN1/ Cyr61. J Cell Biochem. 2007;100:1337-45.

172. Chen CC, Mo FE, Lau LF. The angiogenic factor Cyr61 activates a genetic program for wound healing in human skin fibroblasts. J Biol Chem. 2001; 276:47329-37.

173. Huang YT, Lan Q, Lorusso G, Duffey N, Rüegg C. The matricellular protein CYR61 promotes breast cancer lung metastasis by facilitating tumor cell extravasation and suppressing anoikis. Oncotarget. 2017;8:9200-15.

174. Hirschfeld M, Zur HA, Bettendorf H, Jäger M, Stickeier E. Alternative splicing of Cyr61 is regulated by hypoxia and significantly changed in breast cancer. Cancer Res. 2009;69:2082-90.

175. Dominissini D, Moshitch-Moshkovitz S, Schwartz S, Salmon-Divon M, Ungar $L$, Osenberg $S$, et al. Topology of the human and mouse m6A RNA methylomes revealed by m6A-seq. Nature. 2012;485:201-6.

176. Zhao X, Yang Y, Sun BF, Shi Y, Yang X, Xiao W, et al. FTO-dependent demethylation of N6-methyladenosine regulates mRNA splicing and is required for adipogenesis. Cell Res. 2014;24:1403-19.

177. Bartosovic M, Molares HC, Gregorova P, Hrossova D, Kudla G, Vanacova S. N6-methyladenosine demethylase FTO targets pre-mRNAs and regulates alternative splicing and 3'-end processing. Nucleic Acids Res. 2017;45: 11356-70.

178. Meyer KD, Patil DP, Zhou J, Zinoviev A, Skabkin MA, Elemento O, et al. 5' UTR m 6 a promotes cap-independent translation. Cell. 2015;163:999-1010.

179. Wang X, Lu Z, Gomez A, Hon GC, Yue Y, Han D, et al. N 6-methyladenosinedependent regulation of messenger RNA stability. Nature. 2014;505:117-20.

180. Vu LP, Pickering BF, Cheng Y, Zaccara S, Nguyen D, Minuesa G, et al. The N 6 -methyladenosine ( $m 6$ a)-forming enzyme METTL3 controls myeloid differentiation of normal hematopoietic and leukemia cells. Nat Med. 2017; 23:1369-76.

181. Lin S, Choe J, Du P, Triboulet R, Gregory RI. The m6A methyltransferase METTL3 promotes translation in human cancer cells. Mol Cell. 2016;62:335-45.

182. Chen M, Wei L, Law CT, Tsang FHC, Shen J, Cheng CLH, et al. RNA N6methyladenosine methyltransferase-like 3 promotes liver cancer progression through YTHDF2-dependent posttranscriptional silencing of SOCS2. Hepatology. 2018:67:2254-70.

183. Li F, Yi Y, Miao Y, Long W, Long T, Chen S, et al. N6-methyladenosine modulates nonsense-mediated mRNA decay in human glioblastoma. Cancer Res. 2019:79:5785-98.

184. Rosenwald IB, Wang S, Savas L, Woda B, Pullman J. Expression of translation initiation factor elF-2 $\alpha$ is increased in benign and malignant melanocytic and colonic epithelial neoplasms. Cancer. 2003;98:1080-8.

185. Lobo MVT, Martín ME, Pérez Ml, Alonso FJM, Redondo C, Álvarez Ml, et al. Levels, phosphorylation status and cellular localization of translational factor elF2 in gastrointestinal carcinomas. Histochem J. 2000;32:139-50.

186. Rosenwald IB, Koifman L, Savas L, Chen JJ, Woda BA, Kadin ME. Expression of the translation initiation factors elF-4E and elF-2 $a$ is frequently increased in neoplastic cells of Hodgkin lymphoma. Hum Pathol. 2008;39:910-6. 
187. Rosenwald IB, Hutzler MJ, Wang S, Savas L, Fraire AE. Expression of eukaryotic translation initiation factors $4 \mathrm{E}$ and 2 alpha is increased frequently in bronchioloalveolar but not in squamous cell carcinomas of the lung. Cancer. 2001;92:2164-71.

188. Wang S, Lloyd LV, Hutzler MJ, Rosenwald IB, Safran MS, Patwardhan NA, et al. Expression of eukaryotic translation initiation factors $4 \mathrm{E}$ and $2 \mathrm{a}$ correlates with the progression of thyroid carcinoma. Thyroid. 2001;11: 1101-7.

189. Guo L, Chi Y, Xue J, Ma L, Shao Z, Wu J. Phosphorylated elF2a predicts disease-free survival in triple-negative breast cancer patients. Sci Rep. 2017; 7:44674.

190. Shi Z, Yu X, Yuan M, Lv W, Feng T, Bai R, et al. Activation of the PERKATF4 pathway promotes chemo-resistance in colon cancer cells. Sci Rep. 2019;9:1-8.

191. Zeng H, Zhang JM, Du Y, Wang J, Ren Y, Li M, et al. Crosstalk between ATF4 and MTA1/HDAC1 promotes osteosarcoma progression. Oncotarget. 2016;7: 7329-42.

192. Wengrod J, Martin L, Wang D, Frischmeyer-Guerrerio P, Dietz HC, Gardner LB. Inhibition of nonsense-mediated RNA decay activates autophagy. Mol Cell Biol. 2013;33:2128-35.

193. Tano V, Jans DA, Bogoyevitch MA. Oligonucleotide-directed STAT3 alternative splicing switch drives anti-tumorigenic outcomes in MCF10 human breast cancer cells. Biochem Biophys Res Commun. 2019;513: 1076-82.

194. Jackson KL, Dayton RD, Orchard EA, Ju S, Ringe D, Petsko GA, et al. Preservation of forelimb function by UPF1 gene therapy in a rat model of TDP-43-induced motor paralysis. Gene Ther. 2015;22:20-8.

195. Li L, Geng Y, Feng R, Zhu Q, Miao B, Cao J, et al. The human RNA surveillance factor UPF1 modulates gastric cancer progression by targeting long non-coding RNA MALAT1. Cell Physiol Biochem. 2017;42:2194-206.

196. Jia J, Furlan A, Gonzalez-Hilarion S, Leroy C, Gruenert DC, Tulasne D, et al. Caspases shutdown nonsense-mediated mRNA decay during apoptosis. Cell Death Differ. 2015;22:1754-63.

197. Popp MW, Maquat LE. Attenuation of nonsense-mediated mRNA decay facilitates the response to chemotherapeutics. Nat Commun. 2015;6:6632.

198. Gonzalez-Hilarion S, Beghyn T, Jia J, Debreuck N, Berte G, Mamchaoui K, et al. Rescue of nonsense mutations by amlexanox in human cells. Orphanet J Rare Dis. 2012;7:58.

199. Xue X, Mutyam V, Tang L, Biswas S, Du M, Jackson LA, et al. Synthetic aminoglycosides efficiently suppress cystic fibrosis transmembrane conductance regulator nonsense mutations and are enhanced by ivacaftor. Am J Respir Cell Mol Biol. 2014;50:805-16.

200. Kayali R, Ku JM, Khitrov G, Jung ME, Prikhodko O, Bertoni C. Read-through compound 13 restores dystrophin expression and improves muscle function in the MDX mouse model for duchenne muscular dystrophy. Hum Mol Genet. 2012;21:4007-20.

201. Durand S, Cougot N, Mahuteau-Betzer F, Nguyen C-H, Grierson DS, Bertrand $E$, et al. Inhibition of nonsense-mediated mRNA decay (NMD) by a new chemical molecule reveals the dynamic of NMD factors in P-bodies. J Cell Biol. 2007;178:1145-60.

202. Nickless A, Jackson E, Marasa J, Nugent P, Mercer RW, Piwnica-Worms D, et al. Intracellular calcium regulates nonsense-mediated mRNA decay. Nat Med. 2014;20:961-6.

203. Jia J, Werkmeister E, Gonzalez-Hilarion S, Leroy C, Gruenert DC, Lafont $F$, et al. Premature termination codon readthrough in human cells occurs in novel cytoplasmic foci and requires UPF proteins. J Cell Sci. 2017;130:3009-22

204. Martin L, Grigoryan A, Wang D, Wang J, Breda L, Rivella S, et al. Identification and characterization of small molecules that inhibit nonsensemediated rna decay and suppress nonsense p53 mutations. Cancer Res. 2014;74:3104-13.

205. Nomakuchi TT, Rigo F, Aznarez I, Krainer AR. Antisense oligonucleotidedirected inhibition of nonsense-mediated mRNA decay. Nat Biotechnol. 2016:34:164-6.

206. Kaplan DH, Shankaran V, Dighe AS, Stockert E, Aguet M, Old LJ, et al. Demonstration of an interferon $\gamma$-dependent tumor surveillance system in immunocompetent mice. Proc Natl Acad Sci U S A. 1998;95:7556-61.

207. Van Den Broek MF, Kägi D, Ossendorp F, Toes R, Vamvakas S, Lutz WK, et al. Decreased tumor surveillance in perforin-deficient mice. J Exp Med. 1996; 184:1781-90.
208. Dighe AS, Richards E, Old LJ, Schreiber RD. Enhanced in vivo growth and resistance to rejection of tumor cells expressing dominant negative IFNy receptors. Immunity. 1994;1:447-56.

209. Halliday GM, Patel A, Hunt MJ, Tefany FJ, Barnetson RSC. Spontaneous regression of human melanoma/nonmelanoma skin cancer: association with infiltrating CD4+ T cells. World J Surg. 1995;19:352-8.

210. Saleh FH, Crotty KA, Hersey P, Menzies SW. Primary melanoma tumour regression associated with an immune response to the tumour-associated antigen Melan-a/MART-1. Int J Cancer. 2001;94:551-7.

211. Supek F, Lehner B, Lindeboom RGH. To NMD or not to NMD: nonsensemediated mRNA decay in cancer and other genetic diseases. Trends Genet. 2020;S0168-9525:30307-3.

212. Hargadon KM, Johnson CE, Williams CJ. Immune checkpoint blockade therapy for cancer: an overview of FDA-approved immune checkpoint inhibitors. Int Immunopharmacol. 2018;62:29-39.

213. Waldman AD, Fritz JM, Lenardo MJ. A guide to cancer immunotherapy: from $T$ cell basic science to clinical practice. Nat Rev Immunol. 2020;20: 651-68.

214. Pitt JM, Vétizou M, Daillère R, Roberti MP, Yamazaki T, Routy B, et al. Resistance mechanisms to immune-checkpoint blockade in cancer: tumorintrinsic and -extrinsic factors. Immunity. 2016:44:1255-69.

215. Barrueto L, Caminero F, Cash L, Makris C, Lamichhane P, Deshmukh RR. Resistance to checkpoint inhibition in cancer immunotherapy. Transl Oncol. 2020;13:100738.

216. Tumeh PC, Harview CL, Yearley JH, Shintaku IP, Taylor EJM, Robert L, et al. PD-1 blockade induces responses by inhibiting adaptive immune resistance. Nature. 2014;515:568-71.

217. Ji RR, Chasalow SD, Wang L, Hamid O, Schmidt H, Cogswell J, et al. An immune-active tumor microenvironment favors clinical response to ipilimumab. Cancer Immunol Immunother. 2012;61:1019-31.

218. Goodman AM, Kato S, Bazhenova L, Patel SP, Frampton GM, Miller V, et al. Tumor mutational burden as an independent predictor of response to immunotherapy in diverse cancers. Mol Cancer Ther. 2017;16:2598-608.

219. Lindeboom RGH, Vermeulen M, Lehner B, Supek F. The impact of nonsensemediated mRNA decay on genetic disease, gene editing and cancer immunotherapy. Nat Genet. 2019;51:1645-51.

220. Pastor F, Kolonias D, Giangrande PH, Gilboa E. Induction of tumour immunity by targeted inhibition of nonsense-mediated mRNA decay. Nature. 2010;465:227-30

221. Litchfield K, Reading JL, Lim EL, Xu H, Liu P, Al-Bakir M, et al. Escape from nonsense-mediated decay associates with anti-tumor immunogenicity. Nat Commun. 2020;11:1-11.

222. Oka M, Xu L, Suzuki T, Yoshikawa T, Sakamoto H, Uemura H, et al. Aberrant splicing isoforms detected by full-length transcriptome sequencing as transcripts of potential neoantigens in non-small cell lung cancer. Genome Biol. 2021;22:9.

\section{Publisher's Note}

Springer Nature remains neutral with regard to jurisdictional claims in published maps and institutional affiliations.

Ready to submit your research? Choose BMC and benefit from:

- fast, convenient online submission

- thorough peer review by experienced researchers in your field

- rapid publication on acceptance

- support for research data, including large and complex data types

- gold Open Access which fosters wider collaboration and increased citations

- maximum visibility for your research: over $100 \mathrm{M}$ website views per year

At $\mathrm{BMC}$, research is always in progress.

Learn more biomedcentral.com/submission 